IMPACT FALUURE OF MHW FUEL SPHERE MHFT 65: REPORT ON INTERAGENCY TASK FORCE INVESTIGATION AND SRL EVALUATION OF FAILURE NOVEMBER 1979 - FEBRUARY 1980

\title{
DENNIS H. TAYLOR
}

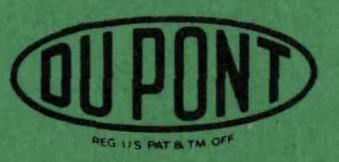

E. I. du Pont de Nemours \& Co. Savannah River Laboratory Aiken, SC 29808 


\section{DISCLAIMER}

This report was prepared as an account of work sponsored by an agency of the United States Government. Neither the United States Government nor any agency Thereof, nor any of their employees, makes any warranty, express or implied, or assumes any legal liability or responsibility for the accuracy, completeness, or usefulness of any information, apparatus, product, or process disclosed, or represents that its use would not infringe privately owned rights. Reference herein to any specific commercial product, process, or service by trade name, trademark, manufacturer, or otherwise does not necessarily constitute or imply its endorsement, recommendation, or favoring by the United States Government or any agency thereof. The views and opinions of authors expressed herein do not necessarily state or reflect those of the United States Government or any agency thereof. 


\section{DISCLAIMER}

Portions of this document may be illegible in electronic image products. Images are produced from the best available original document. 


\section{DISCLAIMER}

This report was prepared by E. I. du Pont de Nemours and Company (Du Pont) for the United States Department of Energy under Contract DE-AC09-76SR00001 and is an account of work performed under that Contract. Neither the United States, the United States Department of Energy nor Du Pont, nor any of their employees, makes any warranty, express or implied, or assumes any legal liability or responsibility for the accuracy, completeness, or usefulness of any information, apparatus, product, or process disclosed herein, or represents that its use will not infringe privately owned rights. Reference herein to any specific commerical product, process, or service by trade name, mark, manufacturer, or otherwise does not necessarily constitute or imply endorsement, recommendation, or favoring of same by Du Pont or by the United States Government or any agency thereof. The views and opinions of authors expressed herein do not necessarily state or reflect those of the United States Government or any agency thereof.

Printed in the United States of Americe

$$
\text { Available from }
$$

National Technical Information Service

U. S. Department of Commerce

5285 Port Royal Road

Springfield, Virginia 22161

Price: Printed Copy A04; Microfiche A01 


\section{IMPACT FAILURE OF MHW FUEL SPHERE MHFT 65: REPORT ON INTERAGENCY TASK FORCE INVESTIGATION AND SRL EVALUATION OF FAILURE MOVEMBER 1979 - FEBRUARY 1980}

DENNISH. TAYLOR

Approved by:

R. L. Folger

Hydrogen \& Ceramic Technology

Publication Date: June 1981

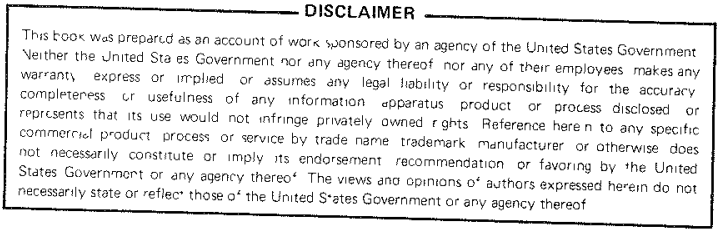

Issued by E. I. du Pont de Nomours 2 Co. Savannah River Laboratory Aiken, SC 29808 
Following a safety verification impact test failure of a Multi-Hundred Watt (MHW) fuel sphere made at Savannah River Plant, from which $2.1 \mathrm{~g}$ of ${ }^{238} \mathrm{PuO}_{2}$ escaped containment, the Department of Energy organized a task force to investigate the cause of the test failure and to assess the failure probability of MHW fuel made at SRP. The task force described a two-part failure mechanism:

(1) embrittlement of the iridium containment shell by phosphorus which may have been picked up from the fuel, and (2) large shear strains in the iridium caused by shearing or "push-through" of large chunks of fuel. Because the likelihood of push-through in this failure model depends on preexisting cracks in the fuel and their orientation to the impact face, the probability of further impact failures could not be easily assessed.

From independent analysis of the available data at the Savannah River Laboratory, we concluded that the impact failure was caused by (1) phosphorus embrittlement of the iridium, and (2) breaching during impact of the graphite impact shell surrounding and cushioning the iridium-clad fuel. Excessive strain in the iridium is caused by extrusion of the iridium into the breach. This model predicts that (1) impact failure is essentially independent of pre-existing cracks in the fuel and (2) that SRP fuel, upon impact, should have no more failures than previously used fuel made at Mound Facility. Impact data to date indicate that SRP fuel clad in DOP-26 iridium cladding actually has fewer impact failures than earlier fuel clad in undoped iridium at MF. 


\section{BLANK}




\section{INTRODUCTION 7}

DESCRIPTION OF FUEL FORM BEING TESTED 8

SUMMARY OF TASK FORCE 11

Objectives of MHFT Task Force 11

Task Force Conclusions 14

Task Force Recommendations 19

Action Items Arising from the Concluding Meeting 19

Areas for Further Research Defined by DOE 23

FAILURE MECHANISM EVALUATION AT SRL 26

Embrittlement of Iridium 26

Effects of Phosphorus on Iridium 26

Sources of Phosphorus in Iridium 36

Effects of High Temperature Aging on Iridium 38

Effects of Oxygen on PICS 39

Effects of other Fuel Contaminants 39

Push-Through Effects: Impact Behavior of MHW Fuel 39

Evidence for Lobe Type Push-Through from Shear

of Large Chunks 40

Evidence Against Lobe Type Push-Through from Shear

of Large Chunks 42

Photograph of Impacted FSA MHFT $61 \quad 42$

Computer Simulation and FSA Geometry 44

Friction and Other Factors as Sources of Statistical

Variability of Strain in Iridium 51 
CONTENTS, Contd

ADDITIONAL RESEARCH RECOMMENDED BY SR TASK FORCE MEMBERS 54

Characterization of Impurities in the Fuel (SRL) 54

Pathways 54

Phosphorus Stability 55

Process Treatments 55

Phosphorus Analys is 55

Effect of Phosphorus on Ductility of Iridium (ORNL) 55

Impact Modeling 55

Fueled Tests 55

SUMMARY AND CONCLUSIONS OF SRL EVALUATION 56

REFERENCES 59 
IMPACT PAILURE OF MHW FUEL SPHERE MHFT 65:

REPORT ON INTERAGENCY TASR FORCE INVESTIGATION AND

SRL EVALUATION OF FAILURE

(NOVEMBER 1979 - FEBRUARY 1980)

\section{INTRODUCTION}

The Savannah River Plant (SRP) makes $238 \mathrm{PuO}_{2}$ fuel forms to power radioisotopic thermoelectric generators for NASA deep space probes. In the first production campaign (completed February, 1980) Multi-Hundred Watt (MHW) spheres about the size of golf balls were produced for the Galileo mission to explore the atmosphere and moons of Jupiter. A second campaign is under way which will make a cylindrically shaped General Purpose Heat Source (GPHS) pellet for use in the International Solar Polar Mission (ISPM) and subsequent missions.

Previously, MHW fuel for space missions was produced at Mound Facility (MF). Later, a different fuel production method was used by the Savannah River Plant for the Galileo mission. The SRP production method was developed by the Los Alamos National Laboratory (LANL) in conjunction with the development of a new iridium alloy developed by the Oak Ridge National Laboratory (ORNL) to encapsulate the $238 \mathrm{PuO}_{2}$. The new fuel process and the new iridium alloy were intended to provide impact survivability superior to that obtained from MF fuel encapsulated in other iridium alloys.

Impact survivability is a condition of flight worthiness of the encapsulated fuel and is intended to prevent $\mathrm{PuO}_{2}$ contamination of the biosphere in the event of a mission failure and reentry of the space vehicle into Earth atmosphere. Simulated reentry impact tests, or Safety Verification Tests (SVT), are conducted at LANL.

A September 1979 Safety Verification Test of an encapsulated fuel sphere, Multi-Hundred Watt Fuel Test (MHFT) 65, showed catastrophic failure of the iridium Post Impact Containment Shel1 (PICS). A large crack (4-cm long $\times 4-\mathrm{mm}$ wide) opened in the iridium PICS, spilling $2.1 \mathrm{~g}$ (vs. $1-10 \mathrm{mg}$ for previous tests) of $238 \mathrm{PuO}_{2}$ into the Graphite Impact Shell (GIS) surrounding the containment shell (see next page, "Description of Fuel Form Being Tested"). The consequence of this test is that the biological hazard source term for the safety analysis using SRP-produced spheres and the ORNL iridium alloy would be one or two orders of 
magnitude higher (less desirable) than that of earlier MF spheres if this undesirable impact result were considered typical of production spheres. A higher biological source term creates concern not only for the flight worthiness of the MHW fuel already produced for Galileo, but also for the GPHS fuel being developed for the International Solar Polar Mission.

In the fall of 1979, an interagency task force was organized by DOE to investigate this catastrophic impact failure of SVT sphere MHFT 65 (SRP Sphere 18). The task force had representatives from SRP, SRL, LANL, ORNL, MF, GE (General Electric), and DOE. After making its recommendations, at the end of February 1980, the task force was disbanded.

The task force ascribed the failure of MHFT 65 to fuel pushthrough coupled with phosphorus embrittlement of the iridium. The task force could not discount this sphere as unequivocally nontypical nor assess the probability of recurrence. The task force agreed that, in general, the SRP-type fuel impacted better than previous fuel and should be used. The results of the task force are presented and discussed in this report.

\section{DESCRIPTION OF FUEL FORM BEING TESTED}

The assembly sequence for an MWW Fuel Sphere Assembly (FSA) is shown schematically in Figure 1. A ${ }^{238} \mathrm{PuO}_{2}$ sphere made in the Plutonium Fuel Form (PUFF) Facility at SRP is encapsulated in thin iridium hemispheres called Post Impact Containment Shells (PICS). The encapsulated fuel, called the Post Impact Sphere Assembly (PISA), is then placed in a Graphite Impact Shell (GIS). In the event of a mission failure and reentry of the Galileo space vehicle into Earth atmosphere, the GIS is designed to absorb the shock of earth impact sufficiently so that the fuel will not breach the iridium containment she 11 and contaminate the biosphere. The final assembly of a PISA within a GIS is called a Fuel Sphere Assembly (FSA). Twenty-four FSAs are assembled, as shown in Figure 2, into a radioisotopic thermoelectric generator ( $R T G$ ).

In the Safety Verification Tests, FSAs are aged, thermally conditioned, and impacted at high velocity using conditions that simulate various accident and reentry scenarios. The success of the test is measured by the amount of $\mathrm{PuO}_{2}$ that escapes from the iridium containment into the GIS; amounts less than about $100 \mathrm{mg}$ are considered acceptable. Success is also measured by the potential for $\mathrm{PuO}_{2}$ escape, such as large cracks in the iridium. Three types of iridium failure modes have been observed: "push-through," hoop, and "fingerprint." Push-through deformation occurs during impact when one part of the PISA is displaced or sheared with respect to an adjacent part. Push-through failure occurs when the 


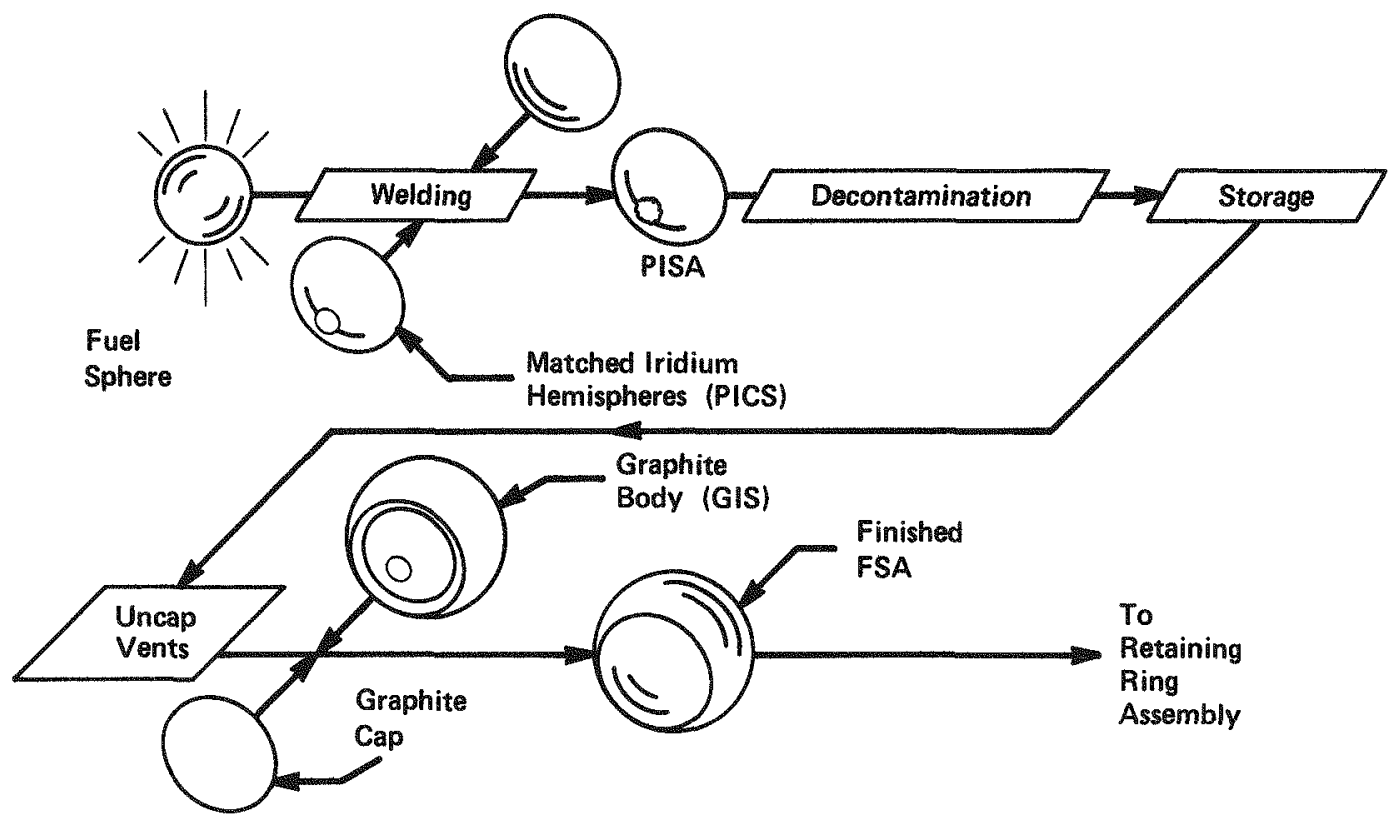

FIGURE 1. Assembly Sequence for Fuel Sphere Assembly 


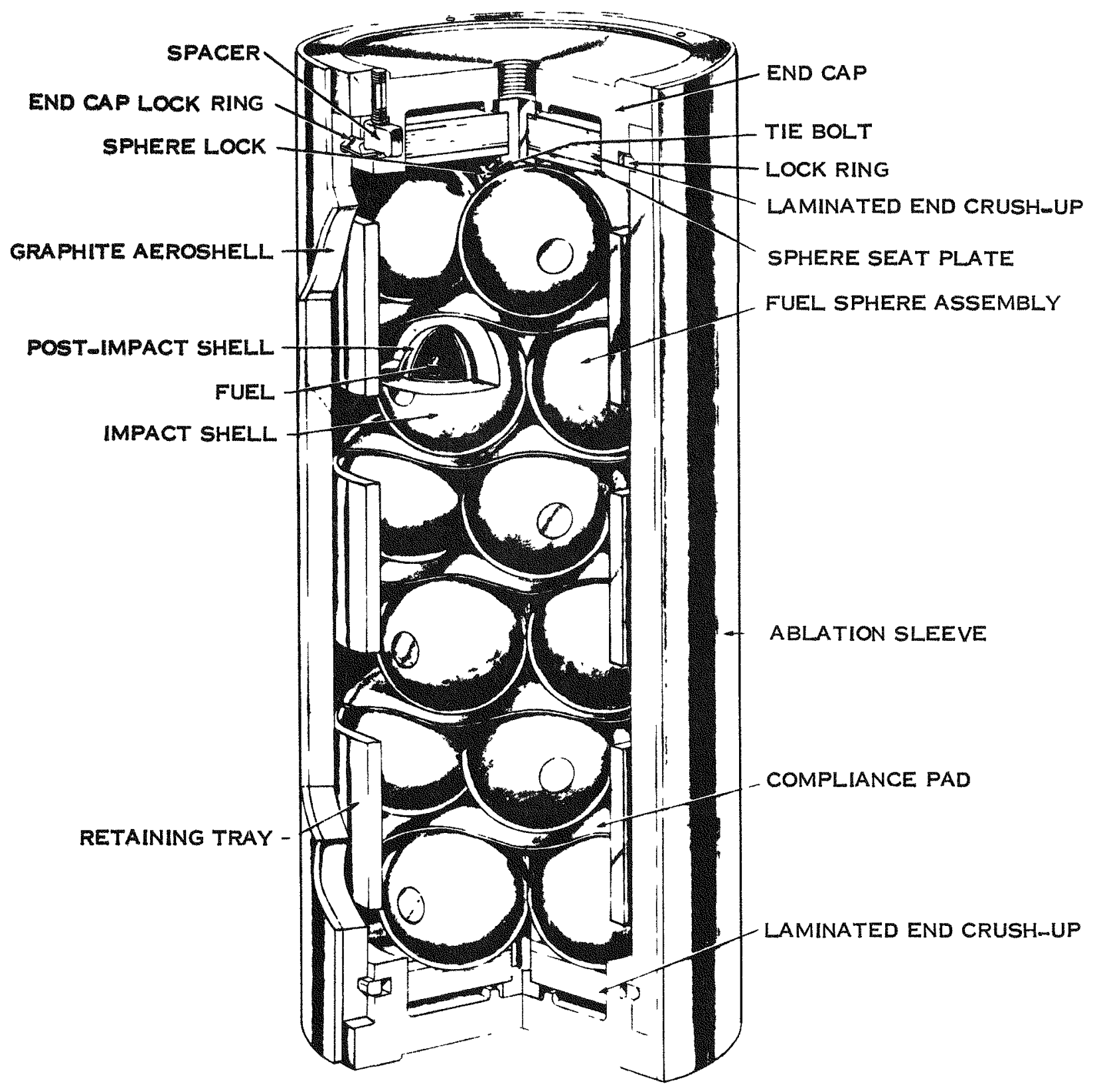

FIGURE 2. Cutaway of Core of MHW Radioisotopic Generator 
relative displacement of the adjacent parts is large enough to exceed the plastic limit of the iridium, and the iridium tears apart. Displacement is approximately normal to the iridium surface. A distinctive "lobe type" push-through deformation is identified as follows: The profile of this type of deformation resembles that of the impact face of a bag of sand dropped onto the edge of a table. Here the unsupported portion of the bag continues farther down the side of the table forming a pronounced "lobe" with the bag experiencing a very sharp bend angle at the edge of the table. The lobe type push-through deformation of MHFT 65 is shown in Figure 3.

Hoop failure occurs at the "bend-over" region where the flattened impact face bends sharply back to meet the normal spherical portion of the PISA. It is perpendicular to the impact face. Hoop failure is caused by excessive lateral expansion of the impact face and is similar to the cracks that develop perpendicular to the equator when a clay ball is squashed. Hoop failures have not been observed in SRP SVTs.

Fingerprint cracks are intergranular cracks that form on the impact face of the iridium in roughly concentric circles resembling a fingerprint. Typically, fingerprint cracks do not penetrate the wall thickness of the iridium and are usually not considered serious.

The large push-through failure of MHFT 65 is shown in Figure 3. The details of this test, and impact tests of SRP fuel through MHFT 67, are summarized in Table 1 . Various analyses were conducted on SRP- and LANL-produced impacted spheres. The most noteworthy results of these analyses were the presence of phosphorus and sulfur in the iridium, compared to previous MF FSAs, and the exceptionally high value of phosphorus in the iridium of MHFT 65 in particular.

\section{SUMMARY OF TASR FORCE}

Objectives of MHFT Task Force

The objectives of the task force were to:

- Determine the probable causes of failure in MHFT 65." .

- Recommend potential near-term solutions for Galileo.

- Assess potential impact on the International Solar Polar Mission (GPHS FUEL).

- Recommend long-term tests and potential improvements. 

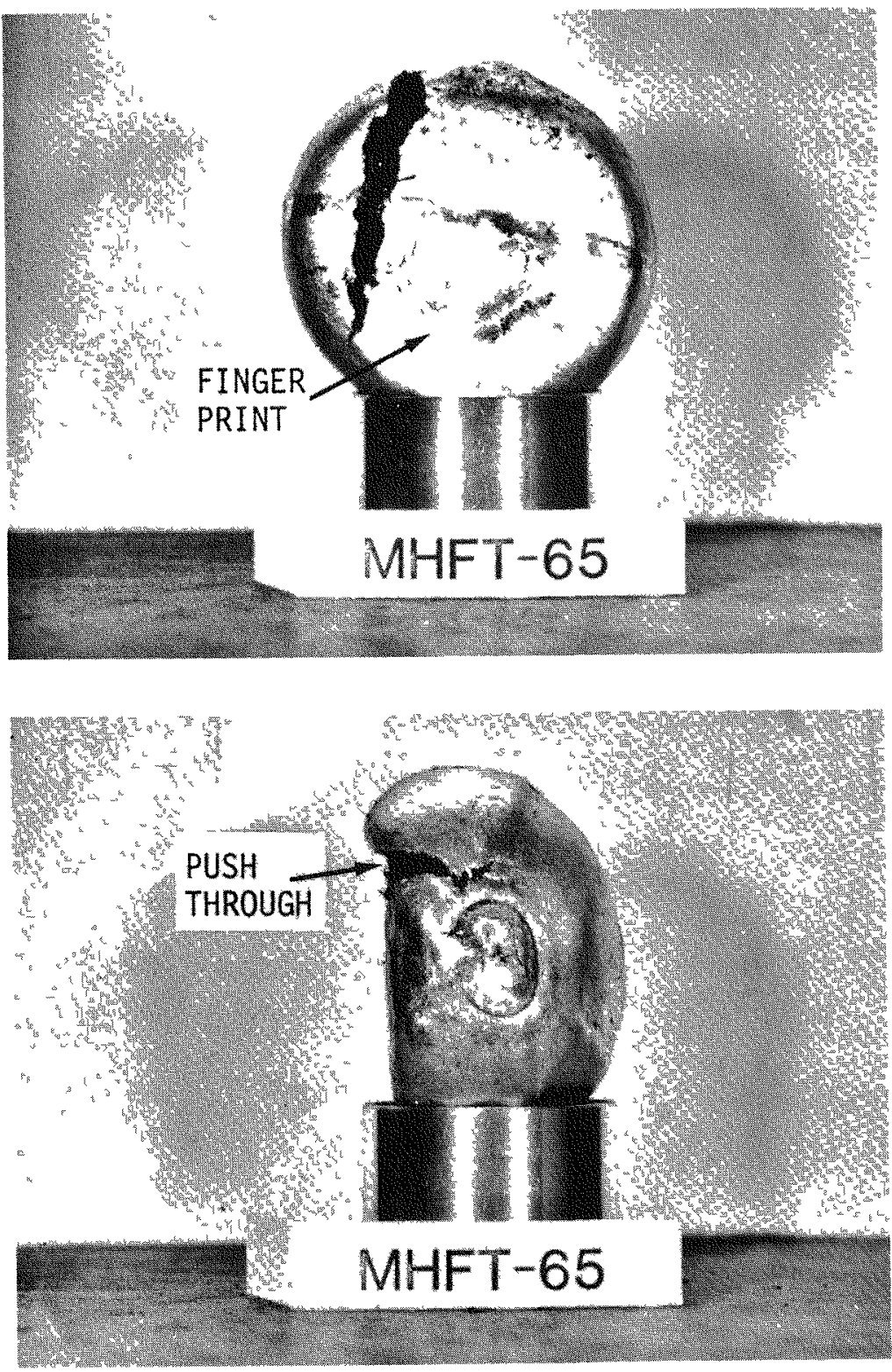

FIGURE 3. Face and Profile of MHFT 65 as a Result of Impact*

* Photographs, courtesy D. Pavone, LANL. 


\section{TABLE 1}

Summary of SR-Fuel Verification MHFT Tests

Type of Fuel

Iridium Type

Fuel, SRP Sphere No.

Impact Velocity, $\mathrm{m} / \mathrm{s}$

Hoop Strain, \%

Failure

$\mathrm{Pu}$ in GIS

Bubble Tèst, for

vents in PISA
MHFT No.

61

$\underline{61}$ -

DOP -26

HDR

DOP-26 DOP-26

HD

DOP -26

HS- 2 HS -11 HS -17 HS -18

85

85

85

HS- 36

74

6.9

12.4

10.8

8.0

85

83

None

FPT* FP*

FPT*

6.9

7.4

NA

$95 \mathrm{mg}$

$2.1 \mathrm{mg}$

$1.85 \mathrm{~g}$

None

None

Open/

open

Open/

Plugged/

plugged
Perforated/ restricted
$<1 \mathrm{mg}$

Plugged/

restricted
NA

Open/

plugged

* FPT = Fuel punch-through.

$\mathrm{FP}=$ Fingerprint.

IGFP = Intergranular fingerprint. 


\section{Task Force Conclusions (See Surmary, Table 2)}

- MHFT 65 failed from push-through deformation.

The mechanism of failure generally accepted by the task force (Table 2) was lobe type push-through deformation caused by the shearing of large "hard" chunks of fuel with the iridium being unable to withstand the strain due to phosphorus embrittlement. There was concern that if the large push-through failure was caused by shear of large pieces along pre-existing cracks as postulated, then later production spheres might be more susceptible to failure. This increased susceptibility was postulated because later production spheres were more crack-resistant and should break up, during handling and storage, into fewer but larger and harder chunks. Impact results for safety verification tests would then be strongly dependent on sphere orientation with respect to the impact face. Therefore, uncertainty would remain on how to weight the tests for impact results.

However, in our view, recent analyses (described later) indicate that the crack network would not have a primary effect on the impact character of spheres. It is our view that the lobe type push-through was not caused by shear of large hard chunks of fuel, but rather by "sandbagging" of the iridium and fuel into a radial breach in the GIS. We agree that failure of the iridium to withstand the resultant strain as did other PISAs (e.g. MHFT 61 under went more strain, without failure, than MHFT 65 ) is the result of too high a phosphorus content. The primary cause of impact failure of the FSA is, therefore, splitting open of the GIS on impact, not shear of large hard chunks of fuel. Although demonstrating this mechanism may not disqualify MHFT 65, it would remove much uncertainty from the SVT results because impact results would not depend strongly on differences in the fuel or on crack orientation.

- There is insufficient data to disqual ify MHFT 65.

The GIS and PICS were typical of Galileo hardware, although the fuel may not have been and the test procedure was not. The sphere (SRP No. HS 18) was a pre-production sphere and may have had a different chemistry, microstructure, and pre-impact crack network than production spheres. The effect of microstructure on sphere impact behavior has not been characterized and, in addition, the microstructure of MHFT 65 before impact cannot be known. Since it is not possible to assess what effect microstructure had, if any, on failure, MHFT 65 must be included in the safety analysis. Although phosphorus embrittlement was generally accepted, the source of the phosphorus in iridium is still uncertain. Hence, too 1 ittle was known about MHFT 65 to disqualify it. More SVTs are needed using spheres of better characterized properties. 
TABLE 2

\section{Conclusions of MHFT Task Force}

- Failure of MHFT 65 is caused by push-through deformation.

- The MHFT 65 must be included in the overall MHW safety analysis.

- LANL/SRP fuel plus DOP-4, 26 iridium have fewer impact failures than previous $M F$ fuel used with undoped iridium.

- Phosphorus decreases the ductility of iridium. Decreased ductility is a possible cause of failure.

- GIS and fuel are sources of phosphorus.

- More data are needed, especially SVTs on production fuel, to confirm that LANL/SRP fuel and DOP-4, 26 iridium are superior to previous MF fuel/iridium.

- Excess oxygen in PISA is harmful.

- Effects of sulfur and other impurities are unknown. 
The fuel sphere assembly of MHFT 65 experienced many thermal cycles during high temperature aging, but the task force could not directly link the cycles to the failure.

- Overal1, the FSAs made with LANL-SRP type fuel and new doped iridium ( $H D$ and DOP-26) alloy impact better than the Mound Facility fuel and undoped iridium originally used.

In making this comparison, Table 3, MHFT 65 is counted as a statistical event and not weighted according to severity. In terms of number of events, the new fuel-iridium system has no hoop strain failures and fewer push-through failures (Table $3 a$ ). In fact, if impact behavior is not strongly dependent on preexisting cracks, as we postulated, then we feel SRP fuel would not be expected to have more push-through failures than Mound Facility fuel. Recent impact results apparently bear this out.

- Phosphorus decreases the ductility of iridium.

Ductility decrease, therefore, could contribute to failure as indicated above. During most of the task force investigation, the effect of phosphorus on ductility of iridium was controversial; LANL had biaxial tensile test data showing no effect; ORNL had uniaxial tensile data showing a detrimental effect. Very recent data from ORNL (presented at the concluding meeting) have shown that the discrepancy may be the result of different concentrations of phosphorus used in the two tests, as described below.

- Both the GIS and fuel are potential sources of phosphorus.

The GIS has a higher bulk concentration of phosphorus, but the relative availability of phosphorus from the GIS or fuel is not known.

- More data are needed on production fuel (from SVTs) in order to assess the safety of SRP fuel.

The performance of flight quality SRP fuel, DOP-26 iridium Fuel Sphere Assemblies, is not known at this time. Even though the total number of impacted spheres having the LANL-SRP type fuel and new doped iridium alloys is beginning to be statistically significant, each test has had differences in fuel fabrication, storage time, test conditions, etc. so that there is no statistical set of impact data on flight quality hardware (SRP fue 1 - DOP-26 iridium). Therefore, the probability of recurrence of a large crack is not known. 
TABLE 3a

LANL Fueled MAW Impact Test Summary

\begin{tabular}{|c|c|c|c|c|c|c|c|c|c|c|c|}
\hline \multirow[b]{2}{*}{$\begin{array}{l}\text { MHFT } \\
\text { Sample } \\
\text { No. }\end{array}$} & \multirow[b]{2}{*}{ Fuel } & \multirow[b]{2}{*}{$\begin{array}{l}\text { Velowity, } \\
\text { fps }\end{array}$} & \multirow[b]{2}{*}{$\begin{array}{l}\text { Temp, } \\
{ }^{\circ} \mathrm{C} \\
\end{array}$} & \multirow[b]{2}{*}{$\begin{array}{l}\text { Aging } \\
\text { Time, }\end{array}$} & \multirow[b]{2}{*}{ Conditrons } & \multirow[b]{2}{*}{$\begin{array}{l}\text { Hoop } \\
\text { Strain } \\
\end{array}$} & \multicolumn{3}{|c|}{ Fazlure Type* } & \multirow[b]{2}{*}{$\begin{array}{l}\text { Ir } 1 d \text { Lum } \\
\text { Lot }\end{array}$} & \\
\hline & & & & & & & Hoop & Fingerprint & $\begin{array}{l}\text { Fuel } \\
\text { "Push- } \\
\text { Through" }\end{array}$ & & \\
\hline 2 & MF & 274 & 1374 & 18 & 1500 & 0.065 & - & -- & -- & $4 \mathrm{~A}$ & \\
\hline 3 & $\mathrm{MF}$ & 276 & 1365 & 18 & 1500 & 0.134 & $\mathrm{x}$ & $-r$ & -- & 5 & \\
\hline 4 & MF & 279 & 1375 & 18 & 1500 & 0.081 & $\mathrm{x}$ & $x$ & -- & $5,4 \mathrm{~A}$ & \\
\hline 12 & $M F$ & 286 & 1480 & 18 & 1500 & 0.088 & $x$ & -- & -- & $15 B, 13$ & \\
\hline 26 & MF & 247 & 1550 & 833 & 1272 & 0.147 & - & $\mathrm{x}$ & -- & 51,50 & \\
\hline 27 & $\mathrm{MF}$ & 249 & 1550 & 833 & 1272 & 0.043 & - & -- & $\mathrm{x}$ & -- & \\
\hline 29 & $M F$ & 253 & 1093 & 720 & 1265 & 0.059 & $x$ & $x$ & $x$ & 51 & \\
\hline 30 & $M E$ & 250 & 1550 & 720 & 1265 & 0.045 & -- & $\mathrm{x}$ & -- & 51,52 & \\
\hline 31 & MF & 243 & 1550 & 720 & 1265 & 0.039 & $\mathrm{x}$ & $-w$ & $x$ & 44 & \\
\hline 32 & $\mathrm{MF}$ & 285 & 1370 & 0 & 0 & 0.075 & - & -- & -.. & $E I-I I I$ & \\
\hline 33 & $M F$ & 282 & 1370 & 0 & 0 & 0.066 & - & -- & - & $F I-1] I$ & \\
\hline 34 & MF & 284 & 1375 & 18 & 1500 & 0.056 & $\cdots$ & -- & $\ldots$ & we & \\
\hline 35 & MF & 281 & 1375 & 18 & 1325 & 0.066 & - & $x$ & $x$ & WC & \\
\hline 36 & MF & 280 & 1375 & 18 & 1325 & 0.069 & - & $\mathrm{x}$ & $\mathrm{x}$ & We & \\
\hline 39 & $\mathrm{MF}$ & 284 & 1100 & 2009 & 1207 & 0.061 & $x$ & -- & $x$ & $W C, \mathrm{n}$ & \\
\hline 40 & $M F$ & 224 & 1440 & 2009 & 1214 & 0.038 & -- & - & $x$ & WC, $\mathrm{n}$ & \\
\hline 45 & $M F$ & 279 & 1440 & 720 & 1214 & 0.083 & $-\cdots$ & $\mathrm{x}$ & $x$ & $E I-I I I$ & \\
\hline 47 & MF & 281 & 1440 & 720 & 1214 & 0.073 & -- & -- & $\mathrm{x}$ & WH & \\
\hline 48 & MF & 285 & 1440 & 720 & 1214 & 0.133 & $x$ & $x$ & -- & WF & \\
\hline 49 & $M F$ & 286 & 1100 & 720 & 1214 & 0.051 & $x$ & $x$ & - & $W F$ & \\
\hline 50 & MF & 281 & 1440 & 731 & 1205 & 0.116 & - & $x$ & $x$ & $\mathrm{FI}-\mathrm{I}] \mathrm{I}$ & \\
\hline 54 & $M F$ & 280 & 1440 & 756 & 1208 & 0.100 & $\mathrm{x}$ & -- & $\mathrm{x}$ & $W C$ & \\
\hline 55 & MF & 285 & 1440 & 777 & 1214 & 0.091 & -- & -- & $x$ & $H D \backslash H D$ & DoP 4 , \\
\hline 56 & MF & 284 & 1440 & 777 & 1214 & 0.066 & $x$ & $\mathrm{x}$ & -- & $\mathrm{HD}$ & \\
\hline \multirow[t]{2}{*}{57} & $\mathrm{MF}$ & 283 & 1440 & 4000 & 1215 & 0.091 & $=$ & $x$ & -- & $\mathrm{HD}$ & \\
\hline & & & & & Percent & facled & 40 & 48 & 48 & & \\
\hline 58 & LANL & 281 & 1440 & 737 & 1210 & 0.081 & $\cdots$ & -- & -- & $\mathrm{HD}$ & \\
\hline 59 & LANL & 283 & 1440 & 737 & 1210 & 0.050 & - & $\rightarrow$ & -- & $\mathrm{HD}$ & \\
\hline 60 & LANL. & 276 & 1440 & 4423 & 1210 & 0.080 & $x$ weld & -- & $?$ & $H D$ & \\
\hline 61 & $S R-2$ & 243 & 1440 & 8834 & 1210 & 0.069 & -- & -- & -- & DOP -26 & \\
\hline 62 & $\mathrm{SR}-11$ & 279 & 1440 & 720 & 1210 & 0.124 & -- & $x$ & $x$ & HDR & \\
\hline 64 & $\mathrm{SR}-17$ & 279 & 1300 & 720 & 1210 & 0.108 & - & $x$ & -- & DOP -26 & \\
\hline 65 & $S R-18$ & 279 & 1440 & 4400 & 1210 & 0.080 & -- & $x$ & $x$ & DOP-26 & \\
\hline 66 & $S R-23$ & 279 & 1440 & 720 & 1210 & 0.069 & - & -- & -- & $H D$ & \\
\hline \multirow[t]{2}{*}{67} & $S R-36$ & 272 & 1440 & 100 & 1200 & 0.074 & $=$ & $=$ & - & DOP -26 & \\
\hline & & & & & Percent & Ealled & 11 & 33 & 33 & & \\
\hline
\end{tabular}

$x=$ Failure confirmed.

$--=$ No fallure. 
TABLE 3b

Types of Iridium*

Iridium Type

"Pure," unalloyed

Undoped, $\operatorname{Ir}-0.3 \% \mathrm{~W}$ alloy

DOP-4, Ir $-0.3 \% \mathrm{~W}$ alloy

DOP-26, Ir $-0.3 \% \mathrm{~W}$ alloy
Lot Designations, last column of Table 3a

$4 A-52, E I-I I I$

WA-WG

WGD, HD, HDR

DOP-26 (also referred to as Types J-M

and OLMF)

* The iridium lots 1 isted in the last column in Table $3 a$ represent four different types. Within each type, the different numbers or letters refer to the sequence of shipment of the powder from the vendor.

TABLE 3c

Compositions of Iridium Alloys*

\begin{tabular}{|c|c|c|c|c|c|c|c|c|}
\hline \multirow[b]{3}{*}{ Element } & \multicolumn{8}{|l|}{ Heat } \\
\hline & \multicolumn{2}{|l|}{ Pure } & \multicolumn{2}{|c|}{ Undoped } & \multicolumn{2}{|l|}{ DOP-4 } & \multicolumn{2}{|c|}{ DOP-26 } \\
\hline & Added & SSMS & Added & SSMS & Added & SSMS & Added & SSMS \\
\hline W, wt \% & 0 & $* *$ & 0.3 & 0.3 & 0.3 & 0.28 & 0.3 & 0.22 \\
\hline $\mathrm{Al}$, wt ppm & 0 & $* *$ & 0 & 5 & 40 & 1 & 50 & 40 \\
\hline Fe, wt ppm & 0 & $* *$ & 0 & 5 & 80 & 1 & 0 & 10 \\
\hline Th, wt ppm & 0 & $* *$ & 0 & $<0.1$ & 30 & 25 & 60 & 50 \\
\hline $\mathrm{Ni}$, wt ppm & 0 & $* *$ & 0 & 1 & 16 & $<0.3$ & 0 & 5 \\
\hline $\mathrm{Rh}$, wt ppm & 0 & $\not * t$ & 0 & 20 & 75 & 40 & 0 & 15 \\
\hline
\end{tabular}

* Table $3 c$ gives typical chemical compositions of the different types of iridium. The "added column" lists the amount of a given impurity added prior to heat treatment. The resultant composition is given in the column labeled SSMS (spark source mass spectroscopy). The resultant varies somewhat, but the values given are considered typical.

** Analyses of individual elements are not available. Total impurities reported by vendor were $<300 \mathrm{ppm}$. 
- Excess oxygen in the PISA is harmful.

Not only does oxygen lead to increased vent plugging due to formation of volatile species, it also reduces the thorium content of the iridium giving rise to increased grain growth with its attendant reduction in ductility.

- The effects of sulfur and other impurities are unknown.

Data concerning the effects of sulfur on any part of the system are not available.

\section{Task Force Recommendations}

The task force recommended that no current changes be made in either the Galileo hardware or planned processing of FSAs. The extent of the problem has not been confirmed in production fuel. Potential solutions (Table 4 ) have not been demonstrated. Therefore, changes in hardware or processing could create an additional risk that is not acceptable. A complete 1 ist of recommendations is given in Table 5 .

\section{Action Items Arising From the Concluding Meeting (February 20, 1980)}

- SRP will catalog low assay side-stream additions for each batch of HB-Line feed powder.

SRP pointed out that one source of phosphorus in the fuel was from the side-stream additions of low assay $238 \mathrm{PuO}_{2}$ (LAP) made to each $\mathrm{HB}-\mathrm{Line}$ precipitation. Since the amount of this side stream addition varied from batch to batch, it is possible that some spheres may have a high phosphorus impurity content even though analyses of several spheres show phosphorus content below $10 \mathrm{ppm}$. DOE requested that all spheres shipped from SRP be cataloged according to percent side-stream addition. Special emphas is was placed on checking whether or not MHFT 65 received an unusually high addition of low assay plutonia that could have led to a high-phosphorus impurity level in the sphere and later the PICS.

This survey was completed quickly by SRP and showed that (1) compared to all production spheres, MHFT 65 had only an intermediate level addition of LAP; and (2) compared to other SVT spheres impacted, MHFT 65 had more LAP (Table 6) than MHFT 61 but much less than MHFT 67, neither of which failed. LAP addition to MHFT 65 does not appear, therefore, to explain the higher phosphorus level observed in the iridium. 


\section{TABLE 4}

\section{Potential Solutions for Galileo}

- Stronger GIS

- shortage of development time

- severe weight penalty

- need to requalify FSA with impact tests

- Treat GIS in Chlorine at $1800^{\circ} \mathrm{C}$ to remove phosphorus

- benefits unknown, phosphorus in GIS not a demonstrated problem

- technology already demonstrated: commercial process

- need more impact tests

- Treat PISA in $\mathrm{H}_{2}$

- facilities not available

- technology not yet demonstrated

- side effects unknown 


\section{TABLE 5}

\section{MHFT Task Force Recommendations}

\section{GALILEO}

- No change in hardware or processing at this time

- extent of problem unclear, not confirmed in production fuel

- potential solutions not demonstrated

- Start long-term aging of additional FSAs immediately

- Evaluate effects of helium during long-term fuel storage

- Continue investigation of methods to remove impurities

- Identify source of phosphorus

- Continue close surveillance of MHFT tests

ISPM

- Tighten fuel specification on impurities: identify limits

- Outgas fuel ( $1 \mathrm{hr} 1500^{\circ} \mathrm{C}$ in vacuum)

- Start long-term aging tests immediately

- Allocate sufficient flight hardware for compatibility tests: establish plan, schedule, and cost

\section{FUTURE MISSIONS}

- Develop ductile fuel with less potential for impurity transport

- Develop cladding having greater ductility, aging stability, and tolerance for impurities 


\section{TABLE 6}

Relative Addition of Low Assay Phosphorus to SVT Spheres

\begin{tabular}{lllll}
$\begin{array}{l}\text { MHFT } \\
\begin{array}{l}\text { Sphere } \\
\text { SVT No. }\end{array}\end{array}$ & $\begin{array}{l}\text { SRP } \\
\text { No. }\end{array}$ & $\begin{array}{l}\text { Low Assay } \\
\text { Side-Stream } \\
\text { Volume, } \%\end{array}$ & $\begin{array}{l}\text { Reduction in } \\
\text { Iridium Wal1 } \\
\text { Thickness at } \\
\text { Push-Through, } \%\end{array}$ & Failure \\
\hline 61 & 2 & 2.395 & $\sim 46$ & None \\
62 & 11 & 3.683 & - & Small push-through \\
64 & 17 & 2.417 & - & "Fingerprint" cracks \\
65 & 18 & 3.590 & $\sim 37-43$ & Severe push-through \\
66 & 23 & 1.94 & - & None \\
67 & 36 & 7.255 & $\sim 37$ & None
\end{tabular}


- Using gamma-ray spectroscopy, LANL wil1 analyze spheres for phosphorus.

LANL will analyze those spheres identified by SRP as having high side stream additions in the feed powder.

- LANL will have metallurgical samples of MHFT 65 analyzed for phosphorus.

Metallurgical preparation may have contaminated these samples (all other pieces were discarded without being analyzed). To help assess this, samples of the plastic mount will also be analyzed.

These sample analyses have been completed and the results are presented in Table 7. MHFT 65, as analysed, is lower in phosphorus than MHFT 61 and 67 . Whether it was lower prior to start of the LANL tests or lower as a result of the aging as reflected in the greater phosphorus content in the iridium, cannot be determined.

- Continue SVT tests using spheres from each production group.

SRP sphere production can be divided into four groups according to production flowsheet modifications made to make more crack.resistant spheres. These efforts were generally successful. Later production spheres should have fewer cracks and larger, more crack-free (harder) pieces after aging. These production groups, together with a summary of process changes, are presented in Table 8 .

\section{Areas for Further Research Defined by DOE}

- Measure the effect of phosphorus in the HB-Line side stream on the concentration of phosphorus in feed powder.

- Determine methods to remove phosphorus from $\mathrm{PuO}_{2}$ at any stage of fuel fabrication (feed, shards, or hot-pressed fuel).

- Measure the effect of phosphorus in the GIS on iridium PICS in a fueled environment.

- Determine a guideline for maximum phosphorus content in iridium. This guideline must be translatable into guidelines for phosphorus in the GIS and the fuel. Current feeling of the task force is that one ppm in iridium is sufficient to cause embrittlement effects. 
TABLE 7

Spark Source Mass Spectroscopic Analyses on GIS and Fuel for Phosphorus for FSAs Used in Safety Verification Tests

\begin{tabular}{llll} 
& \multicolumn{3}{l}{ Phosphorus, ppm } \\
\cline { 3 - 4 } MHFT No. & GIS & Fuel & $\begin{array}{l}\text { Metallurgical } \\
\text { Mounting } \\
\text { Plastic }\end{array}$ \\
61 & 78 & 15 & 5 \\
65 & - & $<10$ & 5 \\
67 & 24 & 15 & 5
\end{tabular}


TABLE 8

Sphere Production Groups

Group Sphere Numbers General Production Conditions

133 through 53

Parabolic load ramp (SVT 67,68 , $69,70,71)$

$\mathrm{T}=1575^{\circ} \mathrm{C}$ or more ( $\mathrm{T}$ is maximum hotpress temperature)

$P=3000-34001 \mathrm{~b}$ force ( $\mathrm{P}$ is maximum hot-press pressure)

$2 a$

54 through 70

(SVT 72)

Linear load ramp

$\mathrm{T}=1575^{\circ} \mathrm{C}$ more consistently

$\mathrm{P}=2500 \mathrm{lb}$ force

Reoxidized in cell atmosphere

$3 \quad 71$ through 81

(SVT 73)

Reoxidized in flowing $\mathrm{O}_{2}$ in final

heat treat furnace at ambient temper-

ature vs. reoxidized in cell atmos-

phere (rapid vs. slow reoxidation)

2b $\quad 82$ through 132

(SVT 74)

Reoxidized in cell atmosphere for

24 hours

$\mathrm{T}=1550^{\circ} \mathrm{C}$, starting sphere 85

otherwise similar to $2 a$

4

133 through

end

$>103.5$ watt spheres vs. 102-102.5-

watt spheres

(SVT 75, 76)

Density increased 1-2\% TD, longer

hot press time - pressure held

during cooldown - spheres 133-139

transition period

Expected crack resistance: $4>2 a$ or $2 b>3>1$ 
- Better characterize the properties and behavior of DOP-26

iridium before investigating new alloys. Emphas is should be on behavior in a fueled environment. The mechanism of phosphorus degradation of iridium should be identified, if possible. Methods to prevent or nullify the effects of phosphorus should be developed.

- Reconcile LANL and ORNL strength tests of doped iridium. Most recent data indicate that apparent contradictions in the LANL and ORNL measurements, of the effect of phosphorus on iridium ductility, can be explained on the basis of different concentrations of iridium in test samples used by each laboratory.

- SRP is requested to investigate the feasibility of using gammaray spectroscopy as a routine phosphorus monitor for powder, shards, or consolidated fuel.

\section{FAILURE MECHANISM EVALUATION AT SRL}

Following the last task force meeting, we summarized and independently evaluated the data presented at the meetings in terms of the two principal causes of failure identified: embrittlement of iridium and push-through effects of the fuel. The results of this evaluation are given below.

\section{Embrittlement of Iridium}

\section{Effects of Phosphorus on Iridium}

The question to be addressed in this section is: Was the failure of the iridium in MHFT 65 due to exceeding the normal plastic limit of the iridium, or, was the failure due to phosphorus embrittlement?

Effects of phosphorus on iridium are not proven, but the available data favor a concentration effect, with a sharp threshold dividing that concentration causing embrittlement from that concentration not causing embrittlement (Figure 4). This concentration effect is based on Auger peak height ratios of phosphorus to iridium at grain boundaries. By coincidence, these peak height ratios are about numerically equivalent to the bulk concentration in ppm.* Therefore, the bulk threshold concentration for phosphorus embrittlement of iridium may be as low as 0.4 to $0.5 \mathrm{ppm}$. As shown in Figure 4, ORNL test data (for a limited number of tests) suggest that tensile test samples with phosphorus-to-iridium

* Private communication with C. T. Liu, Oak Ridge National Laboratory, Oak Ridge, TN. 


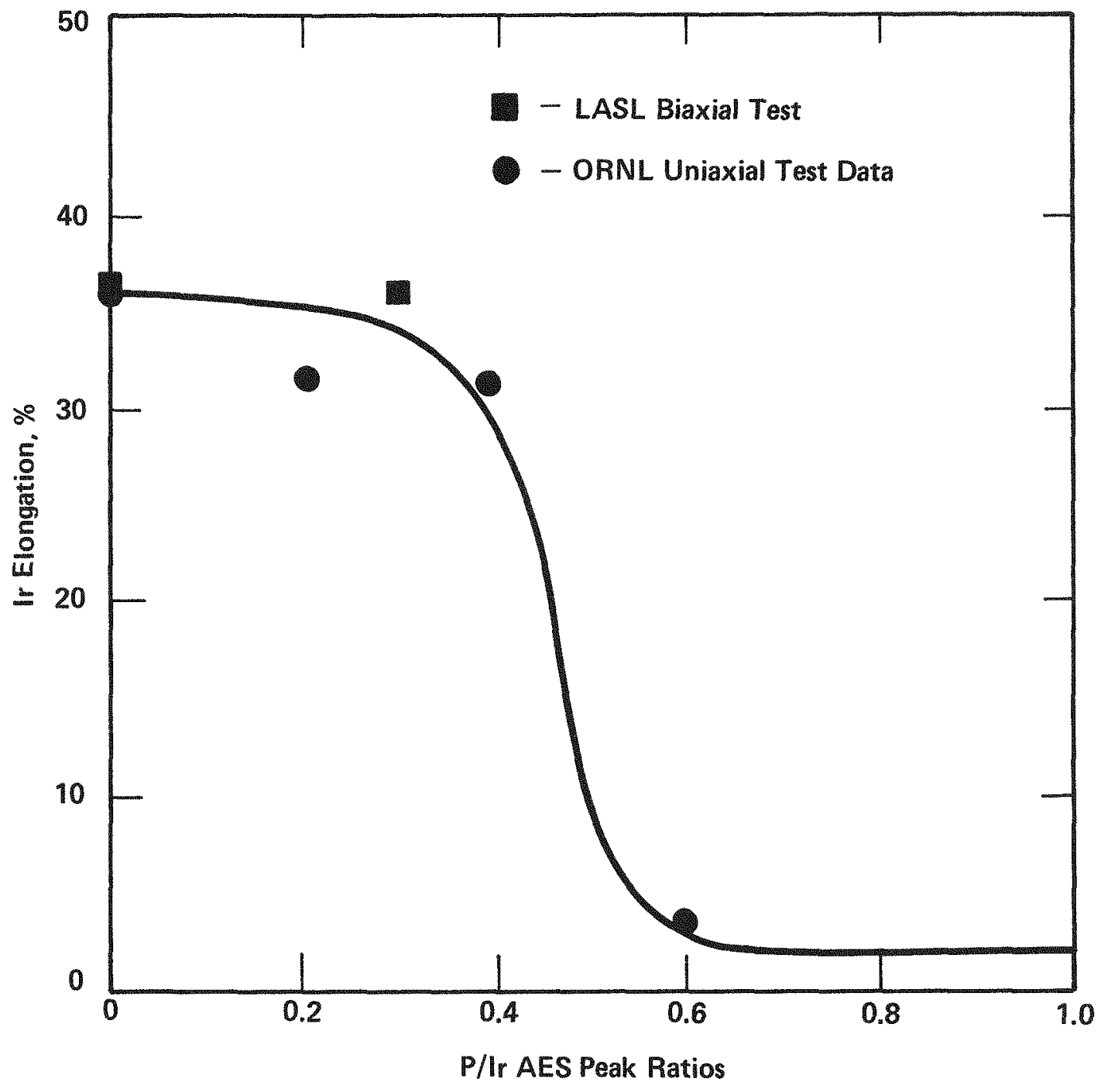

FIGURE 4. Iridium Ductility Vs. Phosphorus Concentration on Grain Boundaries*

* Bulk Concentration of $\mathrm{p}$ in $\mathrm{ppm} \approx$ peak height ratio. 
peak height ratios $>0.5$ exhibit brittle failure, whereas samples with peak height ratios $<0.45$ to 0.50 show ductile failure. Table 9a shows that of all the SRP tests, only MHFT 65 had a phosphorus-to-iridium peak height greater than 0.50 . These data seem to justify the task force belief that the extra phosphorus sufficiently embrittled the iridium so that it was not resistant to strain as much as other spheres. For example, Figure 5 shows that MHFT 61 survived a 46 percent reduction in thickness compared to only 37 to 43 percent for MHFT 65 .

Conditions that lead to embrittlement of crystalline material include large grain size and poor grain boundary bonding. For iridium, in general, the larger the grains, the less the ductility. DOP-26 iridium alloy was developed by adding thorium to keep the grain size sma11. The DOP-26 alloy remains significantly more ductile than earlier alloys used with FSAs (DOP-4 and undoped, see Figure 6) even after oxidation depletes the thorium. Table 10 shows the grain size in terms of the number of grains across the thickness of iridium PICS for four alloys used in the encapsulation of $\mathrm{PuO}_{2}$ fuel. Even after six months of high temperature aging, DOP- 26 iridium shows a smaller grain size. As shown in Table 11, the phosphorus increases the grain size (fewer grains across the thickness of the iridium). Other tests (Table 12) presented by task force members showed that for the same size grains, the ductility was less where phosphorus exceeded the threshold concentration in the iridium. As a further demonstration of this, duplicates of the phosphorus-doped specimens which showed embrittlement were vacuum heat-treated at $1500^{\circ} \mathrm{C}$ for one and two hrs. As shown in Table 12, as the phosphorus level decreased from 0.6 to below 0.5 , the ductility increased. These data demonstrate that phosphorus embrittlement stems not only from larger grains, but, more importantly, from weakened grain boundaries. In Figure 5, MHFT 65 appears to have smaller grains in the strain region than MHFT 61 , but, evidently, weaker grain boundaries allowed MHFT 65 to rupture earlier.

Table 11 shows other possible phosphorus effects. The data suggest that the affect of phosphorus on grain growth in iridium changes with temperature. Annealing temperatures of $1575^{\circ} \mathrm{C}$ appear to have less difference in grain size between doped and undoped iridium than samples at $1500^{\circ} \mathrm{C}$. An unusual possible time effect is also shown. In this case, it appears necessary to maintain the iridium at a high temperature after a short exposure to phosphorus vapor to allow time for the phosphorus to affect grain size. However, somewhat contrary to this observation, in other work reported by ORNL, phosphorus quickly escaped from iridium ( $<2 \mathrm{hr}$ ) when the source of supply of the phosphorus was removed (Table 12).

There is some evidence that thorium or aluminum dopants attract phosphorus to grain boundaries (Table 9). In Table 9a, phosphorus is noticeably more common after thorium and aluminum 

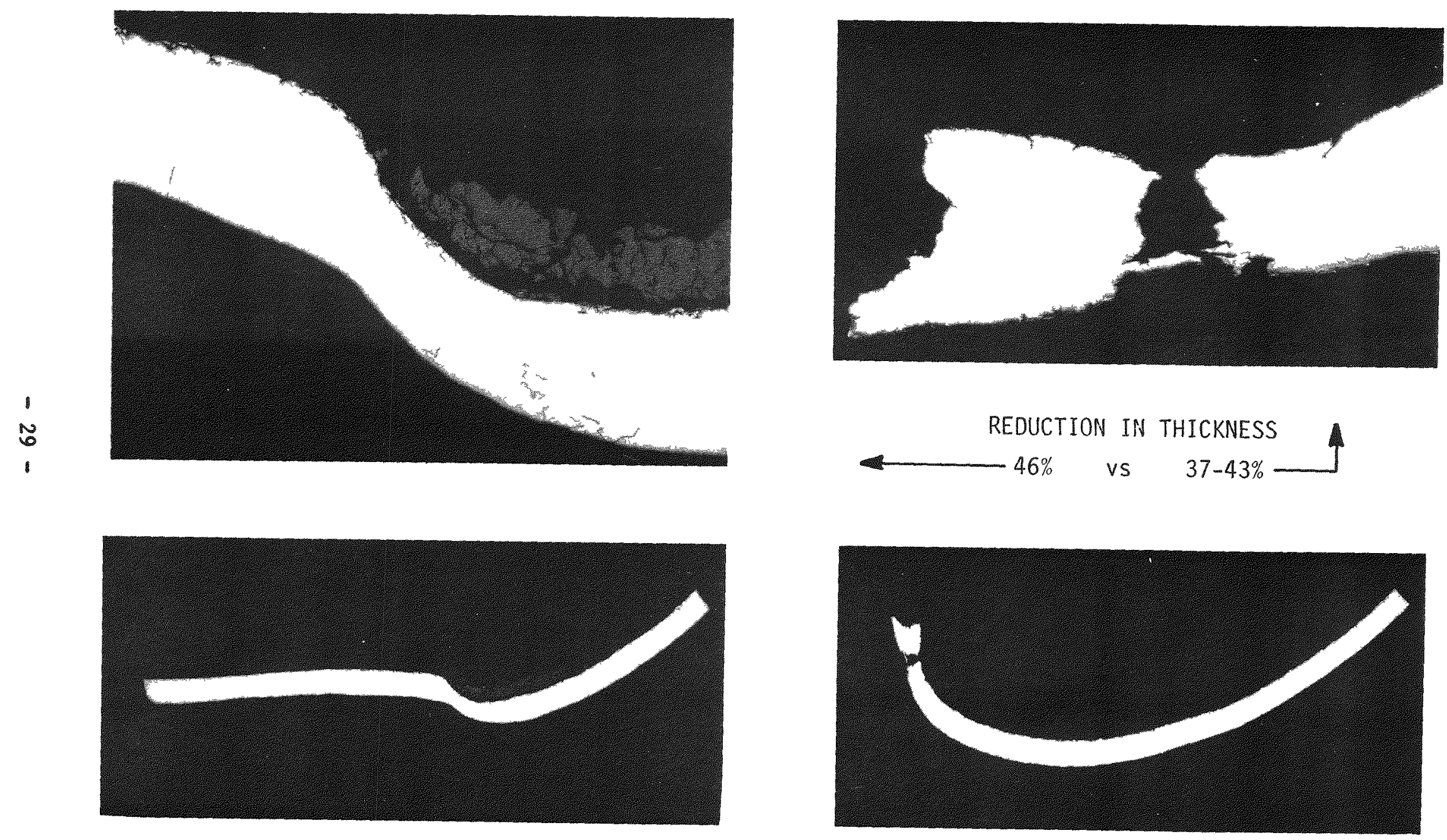

MHFT 61

MHFT 65

FIGURE 5. Comparison of Strain Between MHFT 61 and MHFT 65 


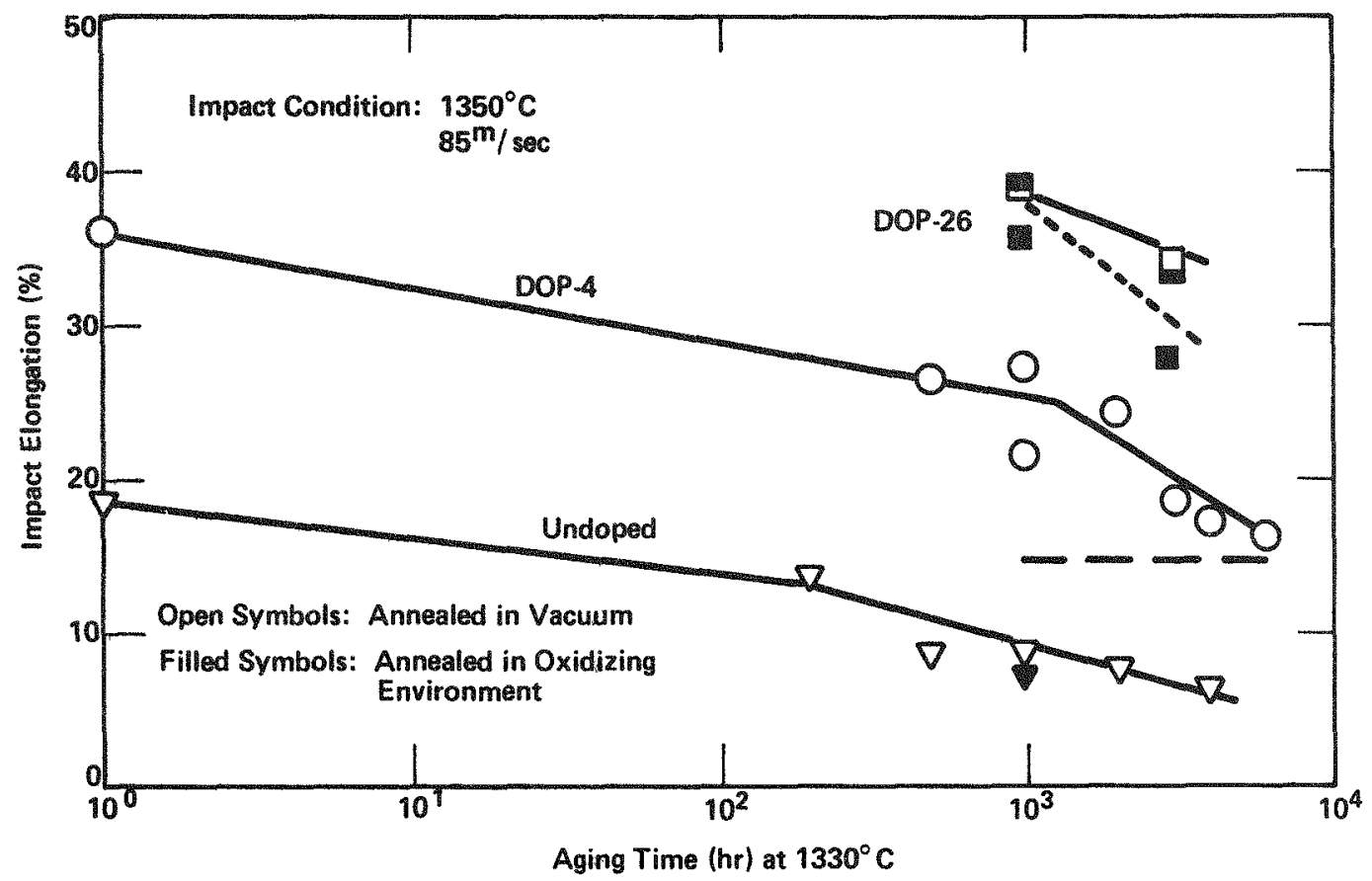

FIGURE 6. Iridium Ductility as a Function of Aging Time and Alloy Composition 
TABLE 9a

Summary of AES Results of Iridium for Live $\left(\mathrm{PuO}_{2}\right)$ FSAs That Were Impacted

\begin{tabular}{|c|c|c|c|c|c|}
\hline $\begin{array}{l}\text { Specimen } \\
\text { MHFT No. }\end{array}$ & $\begin{array}{l}\text { Ir } \\
\text { Type }\end{array}$ & Fuel & $\frac{\text { Auger }}{\text { Th/Ir }}$ & $\frac{\text { Intensity Ratios* }}{\text { P/Ir }}$ & $\begin{array}{l}\text { Major } \\
\text { Impact Failure } \\
\text { Type }\end{array}$ \\
\hline 37 & WC & $\mathrm{MF}$ & 0 & 0 & - \\
\hline 40 & $W C-N$ & MF & 0 & 0 & Push-through \\
\hline 44 & WC-R & MF & 0 & 0.567 & - \\
\hline 47 & WE & $\mathrm{MF}$ & 0 & 0 & Push-through \\
\hline 55 & $\mathrm{HD}$ & MF & 0.32 & 0.03 & Push-through \\
\hline 56 & $\mathrm{HD}$ & $\mathrm{MF}$ & 0.26 & 0.11 & Hoop and fingerprint \\
\hline 57 & $\mathrm{HD}$ & MF & 0.145 & 0.06 & Possible fingerprint \\
\hline 58 & $\mathrm{HD}$ & LANL & 0.272 & 0.027 & None \\
\hline 59 & HD & LANL & 0.387 & 0 & None \\
\hline 60 & HD & LANL & 0 & 0 & Hoop (weld) \\
\hline 62 & HDR & SR & 0.303 & 0 & $\begin{array}{l}\text { Push-through and } \\
\text { fingerprint }\end{array}$ \\
\hline 64 & DOP -26 & $\mathrm{SR}$ & 0.340 & 0.023 & Fingerprint \\
\hline 65 & DOP -26 & SR & 0.286 & 0.58 & $\begin{array}{l}\text { Large push-through and } \\
\text { fingerprint }\end{array}$ \\
\hline 66 & $\mathrm{HD}$ & $\mathrm{SR}$ & 0.457 & 0.088 & Fingerprint \\
\hline 67 & $D O P-26$ & $S R$ & TBD & TBD & None \\
\hline
\end{tabular}

* Found on grain boundaries. Virtually no concentration of these elements in the bulk. 
TABLE 9b

Summary of Phosphorus Pickup by Different Alloys

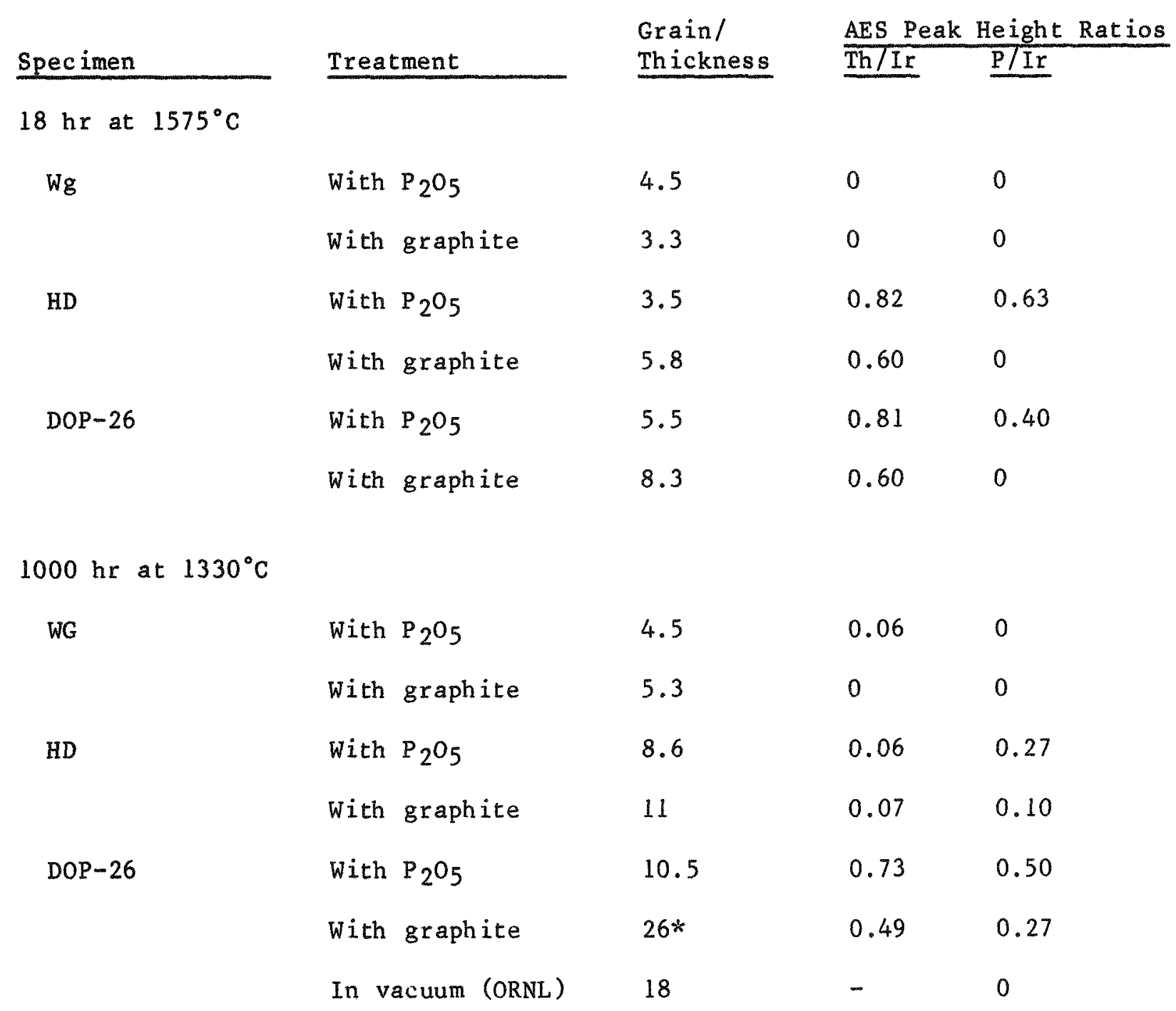

\footnotetext{
* This one data point may be ignored: This grain size is much too fine for DOP-26 Ir-0.3\% W. It is consistent, however, with the grain size obtained for DOP-14 Ir $-0.3 \% \mathrm{~W}(200 \mathrm{ppm}$ Th). A mixup of samples is suspected. The rest of the data are consistent.
} 
TABLE 10

Comparison of Grain Size of Iridium Alloys

\begin{tabular}{|c|c|c|c|c|}
\hline Ir Type & Fuel & Treatment & $\begin{array}{l}\text { No. Grains/ } \\
\text { Thickness } \\
\text { of PICS } \\
\end{array}$ & $\begin{array}{l}\text { No. Grains } \\
\text { Expected From } \\
\text { Vacuum Tests } \\
\end{array}$ \\
\hline WE & MF & $\begin{array}{l}720 \mathrm{hr} \\
1215^{\circ} \mathrm{C}\end{array}$ & $1-3$ & Unknown \\
\hline HD & MF & $\begin{array}{l}777 \mathrm{hr} \\
1215^{\circ} \mathrm{C}\end{array}$ & $2.5-4.5$ & 13 \\
\hline HD & LANL & $\begin{array}{l}737 \mathrm{hr} \\
1215^{\circ} \mathrm{C}\end{array}$ & $4.5-5.0$ & 13 \\
\hline HDR & $\mathrm{SR}$ & $\begin{array}{l}720 \mathrm{hr} \\
1210^{\circ} \mathrm{C}\end{array}$ & 12.6 & 13 \\
\hline $\mathrm{DOP}-26$ & $S R$ & $\begin{array}{l}720 \mathrm{hr} \\
1210^{\circ} \mathrm{C}\end{array}$ & 13.0 & 18 \\
\hline HD & MF & $\begin{array}{l}4000 \mathrm{hr} \\
1215^{\circ} \mathrm{C}\end{array}$ & 3.8 & 7 \\
\hline $\mathrm{HD}$ & LANL & $\begin{array}{l}4423 \mathrm{hr} \\
1210^{\circ} \mathrm{C}\end{array}$ & $1-2$ & 7 \\
\hline DOP -26 & SR & $\begin{array}{l}4400 \mathrm{hr} \\
1210^{\circ} \mathrm{C}\end{array}$ & 5.6 & 12 \\
\hline
\end{tabular}


TABLE 11

Grain Size and AES Results for Phosphorus-Doping Experiments on Ir-0.3\% W (DOP 26)

Al1 Tests Using DOP-26 Iridium

Unusual Time Effect

of Higher

Temperatures

18 hr at $1575^{\circ} \mathrm{C}$

in vacuum

$19 \mathrm{hr}$ at $1575^{\circ} \mathrm{C}$

in vacuum

$19 \mathrm{hr}$ at $1575^{\circ} \mathrm{C}$

in vacuum

$18 \mathrm{hr}$ at $1575^{\circ} \mathrm{C}$

with $\mathrm{P}_{2} \mathrm{O}_{5}$

\section{Grain Size}

No. Grains/

Thickness

$25-28$

19

13

8.7

7.8

4.7

12.6

8.5

0.60

0

7.4

$0.4-0.8$

0

6.2

0.34

0

5.6

0.81

0.40

* All vacuum treatments were done in graphite crucibles. 
TABLE 12

Iridium Ductilicy V8. Phorphorus Content

Sample Treatment, $1500^{\circ} \mathrm{C}$

1. $19 \mathrm{hr}$ in vacuum

2. $18 \mathrm{hr}$ in vacuum, 1 hr with $\mathrm{P}_{2} \mathrm{O}_{5}$

3. Same as 2. above plus $1 \mathrm{hr}$ in vacuum

4. Same as 2. above plus $2 \mathrm{hr}$ in vacuum
Grain Size, no. grains/ thickness

Elongation, $\%$ Reduction in Area, \%

P/Ir, AES

14

36

$>96$, ductile rupture, necked to knife edge

5, intergranu1ar fracture, no necking

94, ductile rupture

$0.4 \quad 12-13 \quad 32$

0.21

12

32

94, ductile rupture 
are added to the iridium. (Data are not available for earlier spheres.) Note that the more frequent occurrence of phosphorus corresponds with a change in iridium more than with a change in fuel. The poor quantitative correlation between thorium concentration at the grain boundary and phosphorus concentration at the grain boundary suggests other influences. Table $9 \mathrm{~b}$ compares doped and undoped iridium alloys heated in the presence of either $\mathrm{P}_{2} \mathrm{O}_{5}$ vapor or phosphorus-bearing graphite. No phosphorus at grain boundaries was found by Auger for WG (undoped) alloy in either treatment, whereas thorium and aluminum doped alloys picked up phosphorus from the $\mathrm{P}_{2} \mathrm{O}_{5}$ vapor and also, after long times, from the graphite. The similarity of grain sizes of the WG iridium for the two treatments tends to confirm the lack of phosphorus pickup. Actinides and aluminum react to form phosphorus compounds that are stable at temperatures over $1500^{\circ} \mathrm{C}$. Such phosphorus compounds may explain the apparent correlation between thorium and phosphorus. However, it is not clear whether the phosphorus compounds will form under any of the conditions seen by the $\mathrm{PuO}_{2}$. Nevertheless, if some type of phosphorus compound is formed, the effect of the compound may be quite different than the effect of phosphorus alone.

In summary, it is clear that phosphorus is detrimental to the strength of the iridium, but the detailed influences of phosphorus on strength, ductility, and grain growth of iridium are not adequately resolved, and further work is needed. This work should be carried out using principles of statistical experimental design so that the effects of phosphorus concentration, temperature, thorium, exposure time, etc. can be delineated.

\section{Sources of Phosphorus in Iridium}

Both the GIS and fuel are candidates for sources of phosphorus. A typical unaged GIS can have from 70 to $140 \mathrm{ppm}$ of phosphorus. This is about an order of magnitude more than has been measured for unaged fuel (Table 13). A comparative analysis for aged GIS and fuel is given in Table 7 for MHFT 61 and 67 . However, the relative availability (ability to contaminate the iridium) of the phosphorus in the GIS and fuel is not known. Since the GIS is a closed system with respect to the PISA inside, there will be a finite partial pressure of phosphorus, within the GIS, in contact with the iridium.

There has been a tendency to discount the GIS as a source of phosphorus because the graphite used is the same as that used for the earlier MF spheres. This should not be done for three reasons. First, the iridium and fuel were not analyzed for phosphorus in most of these earlier tests so that its effect cannot be assessed. Second, impact data comparing MF fuel to LANL-SRP fuel indicate that the MF fuel had more failures (Table 3 ). Hence, if the phosphorus were coming from the GIS it could have been operative then, 


\section{TABLE 13}

Analysis of SRP Feed, Granules, and Spheres for Phosphorus and Sulfur

\begin{tabular}{|c|c|c|c|c|c|c|c|}
\hline Phosphorus & Feed & Granules & Sphere & $\begin{array}{l}\text { MF Sphere } \\
\text { MHF } \\
16^{*}\end{array}$ & $\begin{array}{l}\text { Poco } \\
\text { Graphite } \\
\end{array}$ & $\mathrm{MoS}_{2}$ & Remarks \\
\hline ORNL, SSMS & $0.5-5 \mathrm{ppm}^{* *}$ & $4 \mathrm{ppm}$ & $3 \mathrm{ppm}^{\dagger}$ & $5-100 \mathrm{ppm}^{* *}$ & $10 \mathrm{ppm}$ & - & $\begin{array}{l}\text { Accuracy of a } \\
\text { a factor of two }\end{array}$ \\
\hline SRP, colorimetry & - & - & $<10^{\dagger t}$ & - & - & - & $\begin{array}{l}\text { Some uncertainty } \\
\text { due to bomb } \\
\text { leakage }\end{array}$ \\
\hline LANL, x-ray spec. & - & - & $<20$ & - & - & - & $\begin{array}{l}\text { Detection limit: } \\
\sim 20 \mathrm{ppm}\end{array}$ \\
\hline SRL, SSMS & 6 & $12^{\$}$ & $\begin{array}{l}120^{\dagger t} \\
450\end{array}$ & 70. & - & $\leq 100$ & \\
\hline \multicolumn{8}{|l|}{ Sulfur } \\
\hline ORNL, SSMS & 70 & 300 & $60^{\dagger}$ & $300 * *$ & 100 & - & \\
\hline SRL, SSMS & 5 & $19 \$$ & $\begin{array}{l}180^{\dagger \dagger} \\
3000 * k\end{array}$ & 390 & - & - & \\
\hline
\end{tabular}

* Early Mound Facility sphere used in several qualification radioisotopic generators.

** Widely variable between limits given.

$\dagger$ SRP sphere 146. Unaged.

$\dagger \dagger$ SRP sphere 29. Unaged. SRL SSMS results may have large errors due to contamination.

$\$$ Duplicate of sample sent to ORNL. 
adversely affecting the previous alloys which were generally less ductile to begin with. Third, there is some evidence (Table 9) that thorium-free iridium used for most of the MF spheres may not be as susceptible to phosphorus pickup as the thorium-doped iridium alloy used for MHFT 65. If so, the iridium would not have picked up as much phosphorus even though it was there. In this case, the greater tendency of the MF FSAs to fail may have stemmed from the inherently lower ductility of the iridium alone. These reasons, the last two of which are conflicting, cloud the issue of contamination from the GIS. The GIS, therefore, should not be discounted as a source of phosphorus.

SRP fuel tested shows about $3 \mathrm{ppm}$ phosphorus (Table 13) which is equivalent, if all is transported to the iridium, to about 20 to $30 \mathrm{ppm}$ in the PICS. This level would assure at least one atomic layer of phosphorus on all the iridium grain boundaries and would be expected to be detrimental. However, the availability of the phosphorus in the fuel for transport is not known. Certainly the bulk concentration of phosphorus in the PICS, $<1 \mathrm{ppm}$, shows that not all the phosphorus is transferred from the fuel to the iridium. Phosphorus should also have been in the MF fuel. Mound Facility reports that the phosphorus in SRP feed would be carried along through their process of dissolution and reprecipitation. Helium disruption of the fuel microstructure, after long storage and subsequent high temperature aging, may enhance the availability of phosphorus.

\section{Effects of High Temperature Aging on Iridium}

General ductility decrease with aging (Figure 6) does not explain the impact behavior of SRP fueled FSAs. For example, MHFT 61 (no failure) was aged for $8834 \mathrm{hr}$ at $1440^{\circ} \mathrm{C}$ and showed approximately 46 percent reduction in wall thickness of the PICS after impact. MHFT 65 was aged for less time $(4400 \mathrm{hr})$ at the same temperature, but showed less ductility (from 37 to 43 percent reduction before fracture).

Part of the degradation on aging is the result of grain growth. However, all the grain size variations observed on postmortem analyses of MHFT PICS may not have been due to aging effects. Some variation in the microstructure of (as received) PICS, including localized variations in grain size, has been noted at SRP.*

* Private communication with C. J. Bearden, Jr., Savannah River Laboratory, Aiken, SC. 


\section{Effects of Oxygen on PICS}

Laboratory tests at ORNL show that oxygen depletes the thorium dopant at the grain boundaries and causes the grains to grow. Additional tests have demonstrated that aging in oxygen degrades the ductility of the iridium (Figure 6). The extent of degradation depends on the temperature, exposure time to oxygen, and amount of oxygen present. Hence, an excess oxygen partial pressure within the PICS is expected to adversely affect its impact properties. Calculations done by LANL predict that increased flow through the vents in the PICS will reduce the affect of oxygen. As yet, there is no solid evidence that SRP fuel provides a higher partial pressure of oxygen to the PICS than did the MF fuel.

\section{Bffects of other $\mathbb{P u e l}$ Contaminants}

Sulfur effects on any part of the FSA are unknown.

Likewise, little and inconclusive data are available on iron, chromium, or nickel.

\section{Push-Through Effects: Impact Behavior of MHW Puel}

Failure of MHW sphere MHFT 65 (SRP Sphere 18) on impact focused attention on the importance of pre-impact fracture of the sphere into large integral chunks and their orientation to the impact face as principal causes of fuel lobe type push-through failure of the iridium. However, after considering the evidence available to date, we conclude that:

(1) Lobe type push-through failure of the spheres, such as that seen on MHFT 65 , is not necessarily caused by sliding of a large hard chunk of fuel along an existing crack. Instead, the pronounced lobes are likely caused by sandbagging (or shear of loose and highly broken-up pieces) of the fuel into the resultant gap, following failure of the GIS.

(2) Impact behavior of MHW fuel should not be affected by prem existing cracks in the fuel, or large hard chunks, as long as the GIS remains intact.

(3) If the GIS does fail and lobe type push-through occurs, then the presence of preexisting cracks or hard chunks is not expected to necessarily make lobe type push-through more or less pronounced, or failure of the iridium more or less likely, because the high degree of breakup of the fuel - regardless of its original condition - is expected to cause the spheres to sandbag into the gap in about the same way. 
These deductions are based on (1) evaluation of available LANL impact data, and (2) a computer modeling study performed by Fairchild Space \& Electronics Co., Germantown, Maryland.1

The concern arising from push-through failure of MHFT 65 is with regard to the impact response of the remaining SRP fuel, since MHW production is complete. If shear of large chunks is chiefly responsible for push-through failure, then the later spheres (spheres after MHW Sphere 54) might be expected to have a greater push-through tendency than Sphere 18 (MHFT 65) because these spheres were more fracture resistant and tended to break into larger and stronger pieces after encapsulation.

On the other hand, Spheres 35 through 53, though not as crackresistant, had a greater tendency to fracture into halves or quarters with long, very smooth and flat planes. These pieces were not strong and were easily broken into smaller pieces with irregular fracture surfaces, but the smoothness and flatness of the major fracture plane may provide an easy slip surface along which the smaller pieces could move together as one.

Evidence for and against push-through, as the result of the shearing of large chunks, is presented below. Push-through deformation is any deformation in which one part of the iridium is displaced radially with respect to an adjacent part. Push-through occurs to a greater or lesser extent on most impacted FSAs. How ever, in the discussion that follows, push-through deformation will refer specifically to the formation of pronounced lobes, such as those seen on MHFT 61 and 65. Failure of the iridium is most likely to occur in conjunction with these lobes as it did for MHFT 65. One question that will be addressed is: Do these lobes form as the result of push-through of large integral chunks sliding along pre-existing cracks, or by failure of the GIS followed by sandbagging of small broken up material into the resultant gap?

\section{Evidence for Lobe Type Push-Through from Shear of Large Chunks}

- Shear planes (Figure 7) running from the center axis (perpendicular to the impact face) of impacted sphere MHFT 61 toward the push-through area of the impact face, form nearly an isosceles triangle. The triangle's base is along the impact face, and the triangle's apex is along the center axis about $2 / 3$ to $3 / 4$ of the distance from the impact face to the rear of the sphere. It is hypothesized that as material below these planes began to be slowed, large chunks above the planes slid along the planes and sheared the iridium PICS. 


\section{PRE-EXISTING}

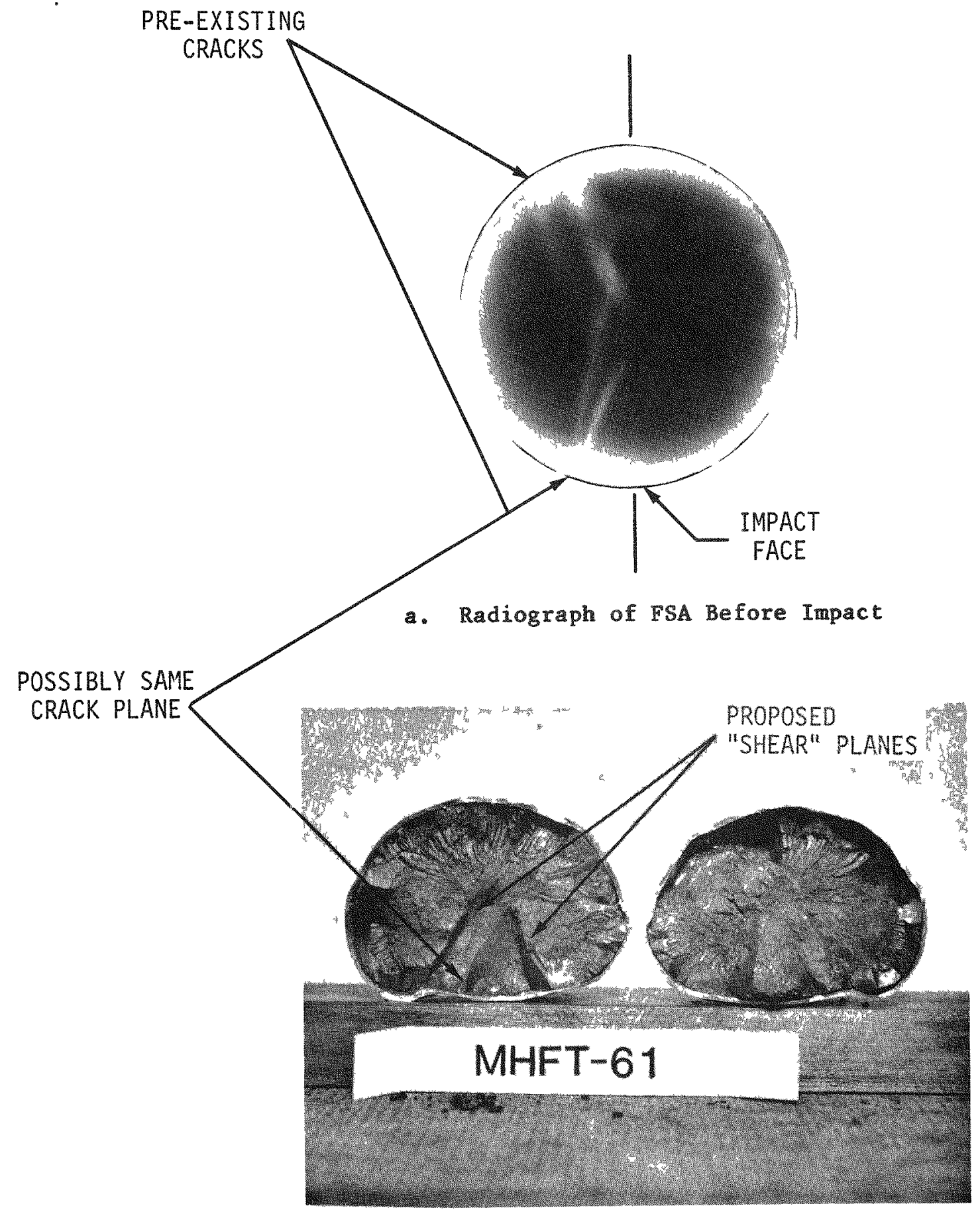

b. Section After Impact

FIGURE 7. SRP Test Sphere MHFT 61*

* Photographs, courtesy D. Pavone, LANL. 
- Dislocation of the iridium along a shear plane from the back of the sphere to the point of potential push-through suggests motion of a piece of sphere (Figure 8, MHFT 70). MHFT 70 demonstrates that push-through deformation (although not necessarily lobe type) can occur as the result of the shear of large masses of fuel (either intact or as many small pieces acting in concert) along a single fracture plane.

\section{Evidence Against Lobe Type Push-Through from Shear of Large Chunks}

\section{Photograph of Impacted FSA MHFT 61 and FSA MHFT 70}

- Shear planes are symmetric around the center axis of Sphere MHFT 61, but push-through deformation occurs only along one plane. There should be an equivalent shearing deformation along the other plane. Also, the apex of the shear plane is not at the back surface of the sphere, but in the body. For example, the shear plane does not seem to extend all the way through as would be the case for shear of a large chunk or mass along the plane (cf MHFT 70). In addition, the crack seen in the radiograph appears to correspond better to a different crack plane (see Figure 7) than to the shear plane leading into the push-through. However, the orientation of the radiograph may not be known accurately enough for such a distinction.

- Small particles in spheres range from 1 to $10 \mathrm{~mm}$ in diameter. Large chunks have not been observed as might be expected if they were strong enough to be pushed through, as a chunk, during impact.

- Lack of prominent lobes on the impact face of MHFT 70 showed that deformation can occur by the sliding of large masses, without significant lobe type push-through deformation. Only two small such displacements occurred in the impact face. One of them barely penetrated the iridium.

Pre-impact radiographs of Sphere MHFT 70 (SRP Sphere 39) showed that it was completely separated into two hemispheres along a flat pole-to-pole plane with the fracture plane oriented in the same direction, with respect to the impact face, as the deformation line shown in Figure 8. PuFF records show that this sphere had fractured prior to gauging and had to be assembled into the PICS for welding. This gave rise to the very large separation of two hemispheres seen in the radiograph. That the two halves appeared physically separated in the radiograph, and had been reassembled, suggests that they may have been kept apart by small particles and asperities which would have helped the two pieces slide over one another. 


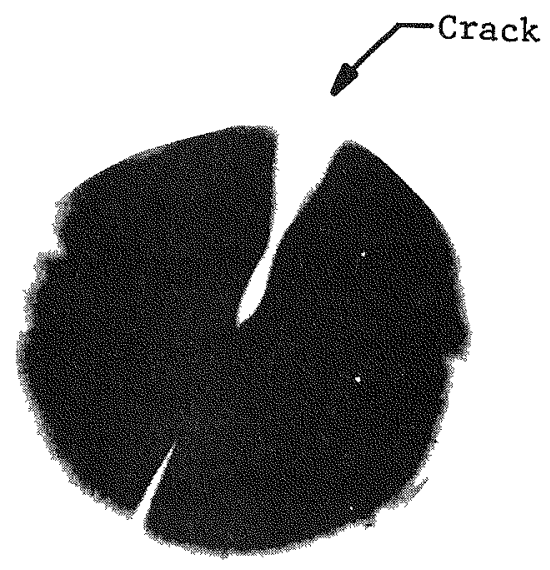

a. Radiograph of Sphere Before Impact

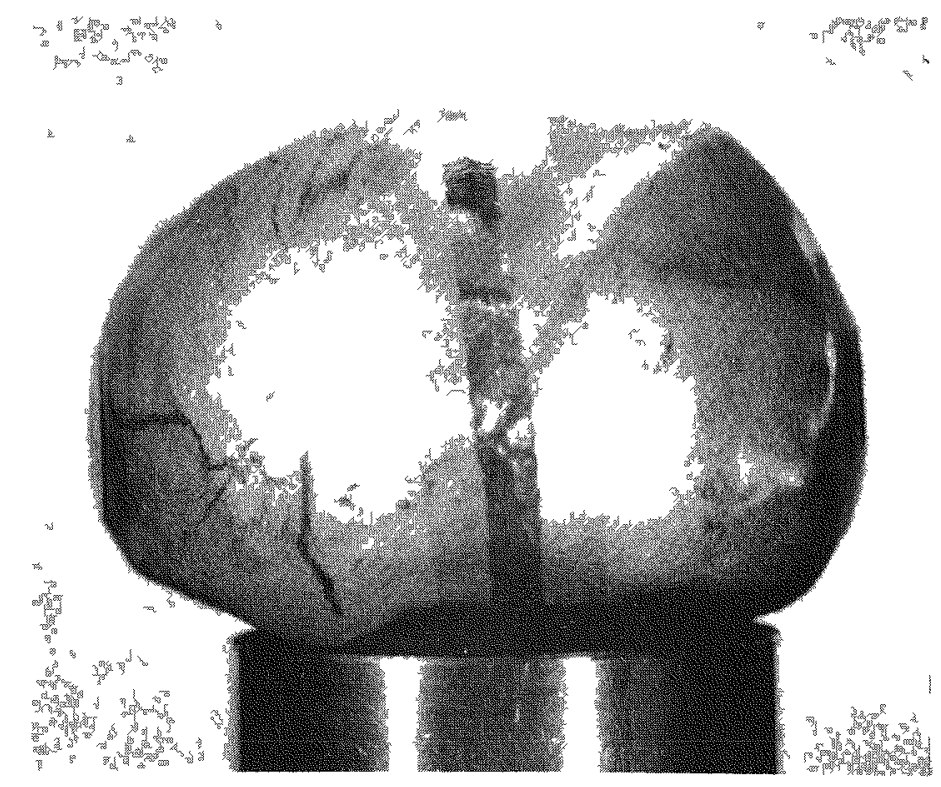

b. Deformation From Shear of Two Halves of Sphere. No Push-Through Failure

FIGURE 8. Impact of MHFT $70 \%$

* Photographs, courtesy D. Pavone, LANL. 
The condition of MHW Sphere 39 is expected to be unusual for spheres past SRP Sphere 53 since (1) these later spheres usually remained intact during encapsulation, and (2) these spheres tended not to break into hemispheres or quarters along smooth planes, as was the tendency with those Spheres 35 through 53 which did break. Sphere MHFT 70 is expected to be unusual, further, because Spheres MHFT 67, 68, and 69 (SRP Spheres 36, 37, and 38) did not deform in the manner of MHFT 70, yet they are sister spheres from the same production group.

\section{Computer Simulation and FSA Geometry}

Lobe type push-through deformations of the magnitude observed in MHFT 61 and 65 and others are not possible without failure (i.e. radial splitting open) of the GIS. The hypothesis that the shear of large fuel pieces causes lobe type push-through is understood to mean that the pieces of fuel pass over each other and push through the iridium before the iridium contacts the GIS at the point of push-through; otherwise, without failure of the GIS, push-through could not occur. Evidence against this hypothesis is provided by FSA geometry and computer modeling of impact.

From the geometry of the FSA at the instant of impact, it can be shown that the radial gap between the PISA and the GIS at the point where the push-through was observed for MHFT 61 is less than the estimated radial displacement observed so that the displacement could not have occurred without deformation or failure of the GIS.

Figure 9a shows the geometry of the FSA at the moment of contact of the PISA with the GIS. (Deformation of the inner radius of the GIS due to its own impact is considered negligible at this early time.) Points along the PISA circumference corresponding to different $d / D$ ratios used in the computer modeling are labeled $w, x, y$, and $z$. These same relative points are shown for comparison on the cross section of impacted MHFT 61 (Figure 9b). Point $x$ corresponds very closely with the point of contact of the hypothesized push-through or shear plane of the pieces of fuel. In Figure 10, the calculated radial gaps ${ }^{2}$ for each of the points are compared with the maximum radial shear experienced by the pushthrough in MHFT 61, estimated as shown in Figure 11. Though the radial displacement of the MHFT 61 push-through is difficult to determine accurately, it is clearly larger than the radial gap between the GIS and PISA. Hence, to accommodate the displacement observed, the GIS had to give way.

Computer simulations of impact show that, before the fueliridium impact, the GIS-iridium impact occurs at points corresponding to the point of push-through seen in MHFT 61 and other spheres. Figure 10 shows the geometry of the FSA at the moment of impact and 


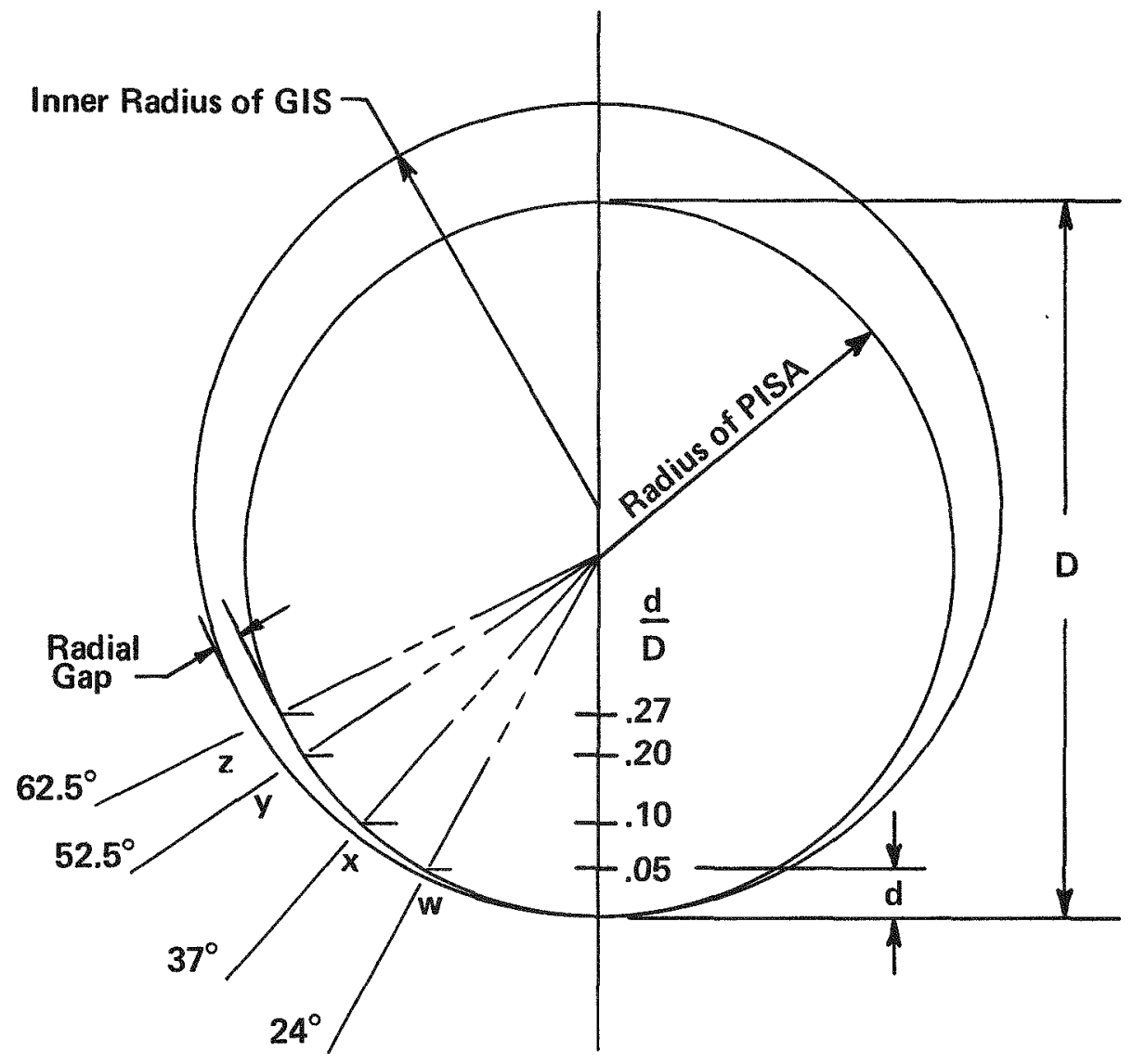

a) Geometry at Instant of Impact of PISA Into GIS (neglecting small deformation of GIS already started)

\section{Approximate}

Push-Through Point

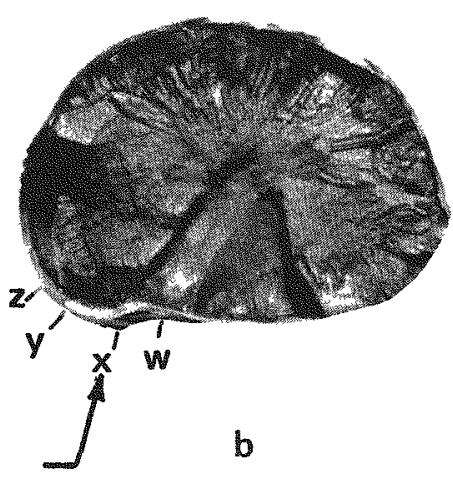

b) Extrapolation of Points $W, X, Y, Z$ to Impacted MHFT 61

FIGURE 9. Impact Geometry of FSA 


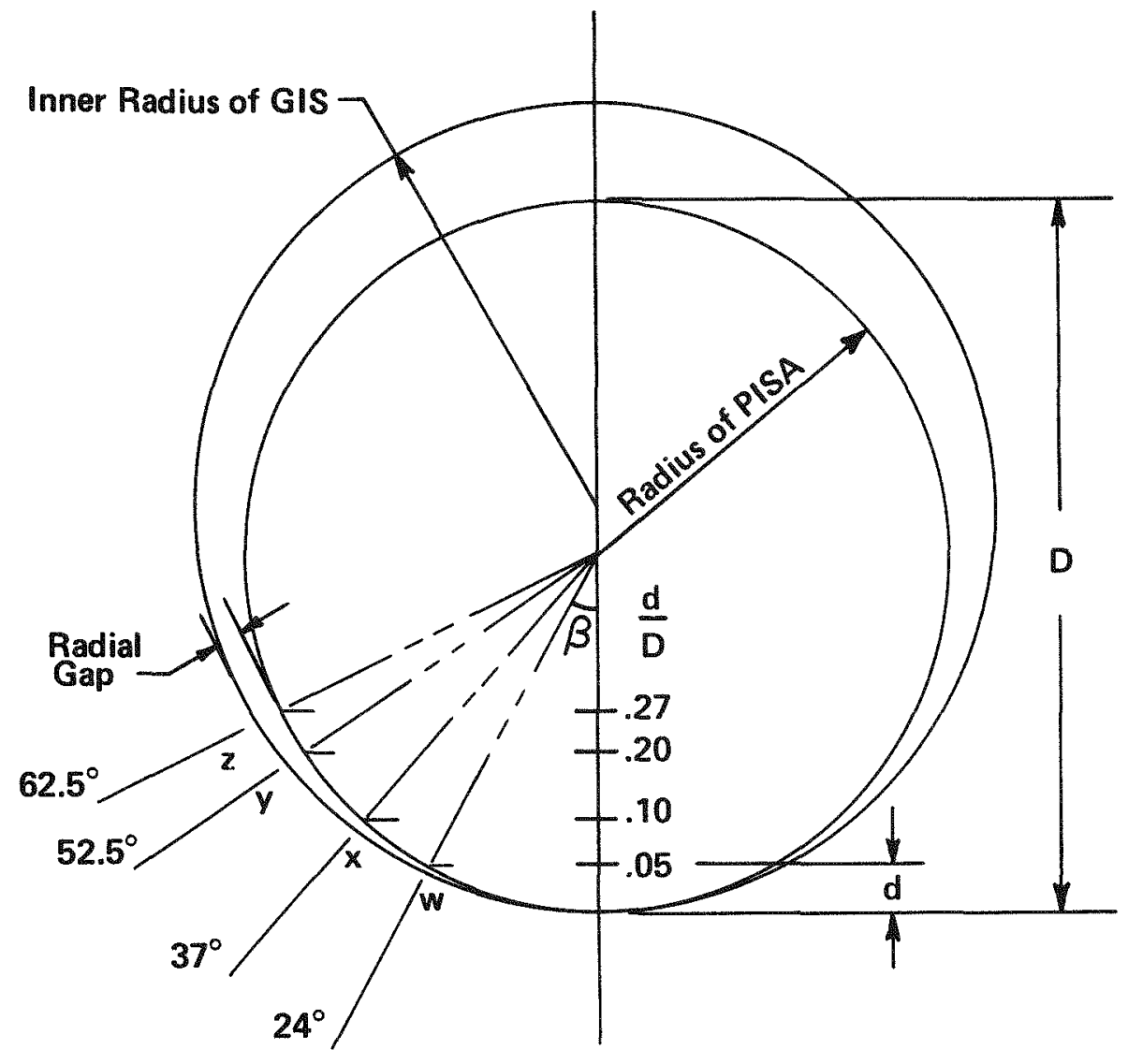

\begin{tabular}{|c|c|c|c|c|}
\hline$\frac{\mathrm{d}}{\mathrm{D}}$ & $\begin{array}{c}\text { Initial } \\
\text { angle, } \\
\beta \\
\end{array}$ & $\begin{array}{c}\text { Initial } \\
\text { radial gap, * } \\
\text { in. } \\
\end{array}$ & $\begin{array}{c}\text { Relative } \\
\text { Ir-GIS, } \\
\text { usec } \\
\end{array}$ & $\begin{array}{c}\text { Impact Times** } \\
\text { Fuel-Ir, } \\
\text { usec }\end{array}$ \\
\hline 0.05 & 24 & 0.004 & 17 & 45 \\
\hline 0.10 & 37 & 0.009 & 28 & 53 \\
\hline 0.20 & 52.5 & 0.016 & 52 & 72 \\
\hline 0.27 & 62.5 & 0.023 & 72 & 83 \\
\hline
\end{tabular}

Maximum radial displacement of push-through for MHFT 61 is estimated from Fiq. 11 to be $\sim 0.090$ in.

*Based on I.D. of GIS $=1.632$ in.; O.D. of PISA=1.550 (see Ref. 2).

**Based on computer model "FSA 4": Strong GIS-Hard fuel-friction between GIS-Ir and Fuel-Ir. However, all other computer models

(e.g. Strong GIS - Weak fuel - no friction) also showed the

same relative impact sequence up to $d / D=0.15$ (Ref.1).

FIGURE 10. Initial Contact Geometry of FSA 


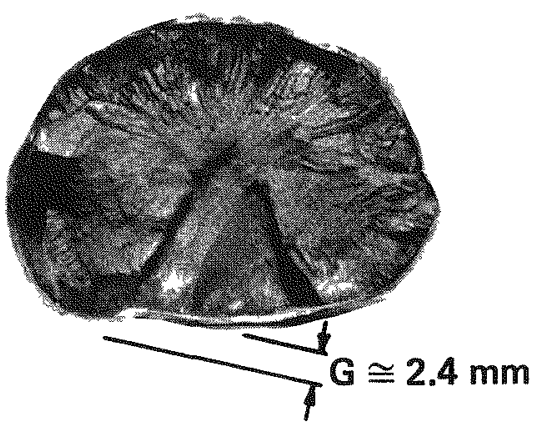

Scale Factor to Reduce G to Actual Size $=0.916$

$\therefore G_{\text {Actual }} \cong 2.2 \mathrm{~mm}=0.087 \mathrm{in}$

a. Calculation From Photograph

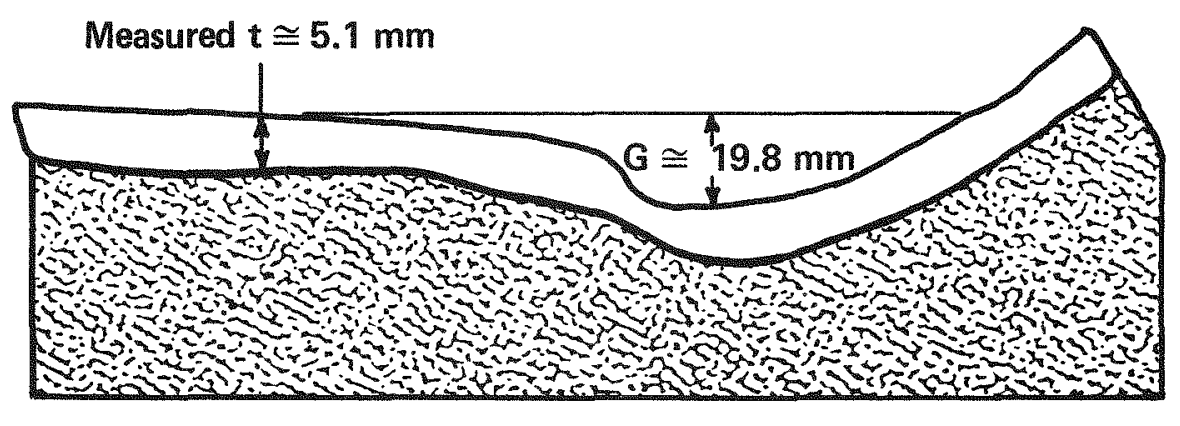

Actual Thickness t of Iridium $=0.024$ in

$\therefore$ Estimated Displacement, $G=\frac{19.8}{5.1} \times 0.024=0.093$ in

Ave. of both determinations $=0.090$ in

b. Calculation From Drawing of Metallographic Mount of iridium

FIGURE 11. Estimation of Radial Push-Through Deformation of MHFT 61 *

* Photographs, courtesy D. Pavone, LANL. 
the times of contact for points $w, x, y, z$ around the sphere. At all these points, the fuel does not contact the iridium before the iridium contacts the GIS. Once again, push-through would not be possible without failure of the GIS.

The stress for failure of the GIS, aside from that arising from its own impact, comes from the lateral expansion of the fuel as illustrated in Figure 12 (where the loci of points in an und isturbed sphere are plotted for deformation during computer-simulated impact). It should be remembered that the intent of the GIS is to provide restraint for the lateral expansion of the PISA to prevent hoop failure of the iridium. Therefore, where the GIS fails, the push-through and breaching of the iridium should be expected. Evidence for failure of the GIS is given in Figure 13a and illustrated schematically in Figure 13b. As shown in Figures $13 \mathrm{~b}$ and $13 \mathrm{c}$, the proposed mechanism of push-through deformation is the failure of the GIS and sandbagging of the fuel into the resultant gap. This mechanism explains the very distinct lobes observed in the pushthrough. At the inner 1 ip of the gap, very large strains and strain rates would occur making this point the most probable point of iridium tearing as observed in MHFT 65.

The computer simulation shows that at the estimated time of failure of the GIS, the fuel still has sufficient energy to sandbag into the opening in the GIS. Total impact time for the FSA has been measured to be about $200 \mathrm{usec}$. According to the computer model, the impact face has flattened out to the point where the push-through occurred in MHFT 61 and MHFT 65 in about $100 \mu \mathrm{sec}$. By this time, the model shows that the fuel has over half of the energy it will eventually spend in distortion still present as kinetic energy. Hence, when the GIS fails, ample energy remains for the fuel to sandbag into the gap.

It might be argued that the large fuel pieces shear across each other on the pre-existing crack with such force that they still cut through the iridium and wedge open the GIS. However, the computer model does not support this view. Before $100 \mu \mathrm{sec}$, the model shows spallation along the surface of the sphere which would blunt the tips of the pieces. Moreover, the model shows considerable fuel breakup has occurred by $100 \mathrm{usec}$, so that the large chunks would have been broken up.

Summing all the evidence given in this section, it appears that the impact resistance of SRP fuel does not depend strongly on the nature of large pre-existing cracks. Both from the point of view of the available gap between the iridium and GIS and the relative GIS-iridium and fuel-iridium impact times, the data on the mechanics of impact of FSAs indicate that lobe type push-through deformation could not occur unless the GIS also failed. When the GIS fails, lobe type push-through can occur by sandbagging of the 


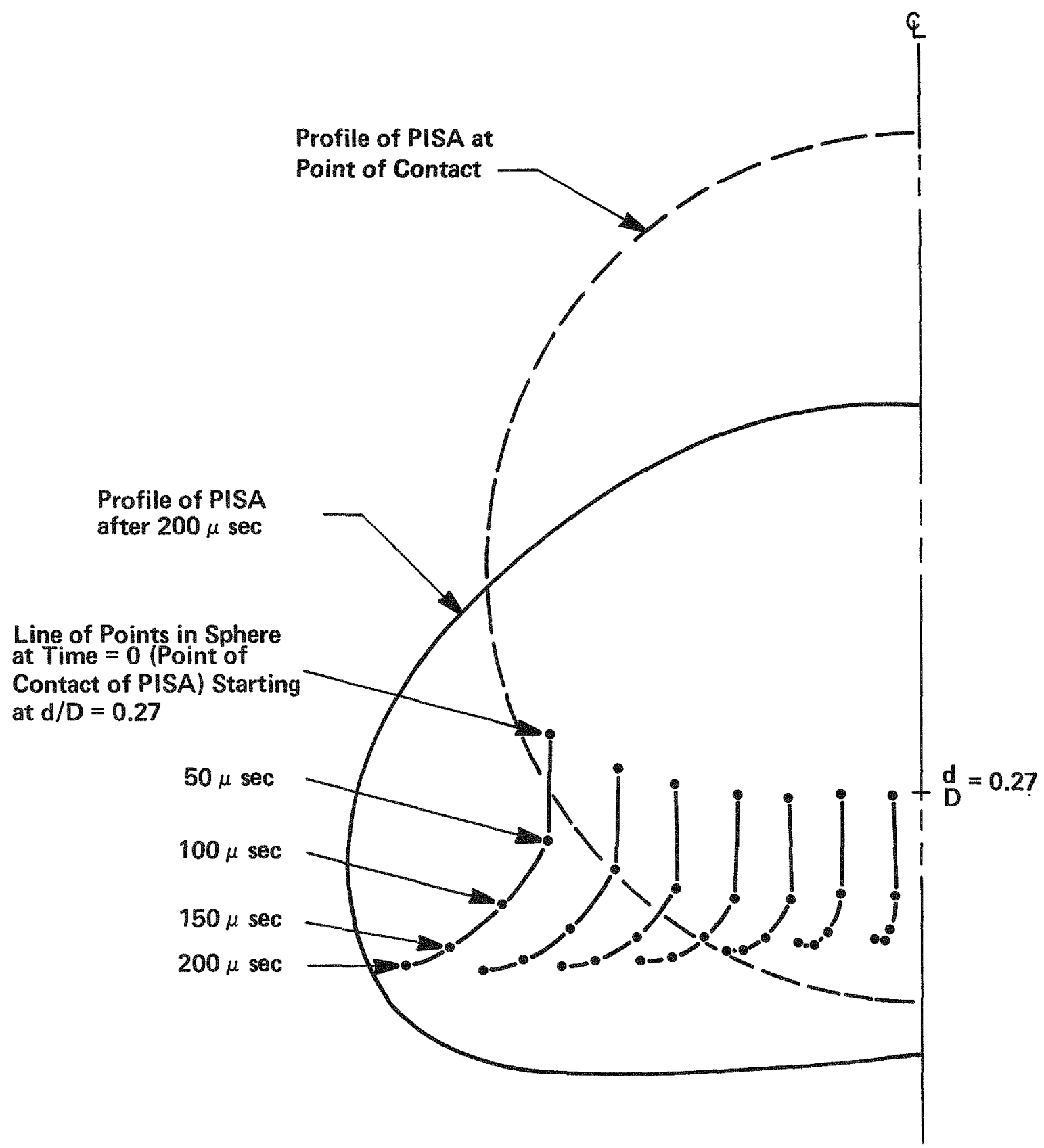

FIGURE 12. LOCI of Points in Fuel During Impact Showing Lateral Thrust Near End of Impact*

$\because$ FSA 4 in Reference 1. 

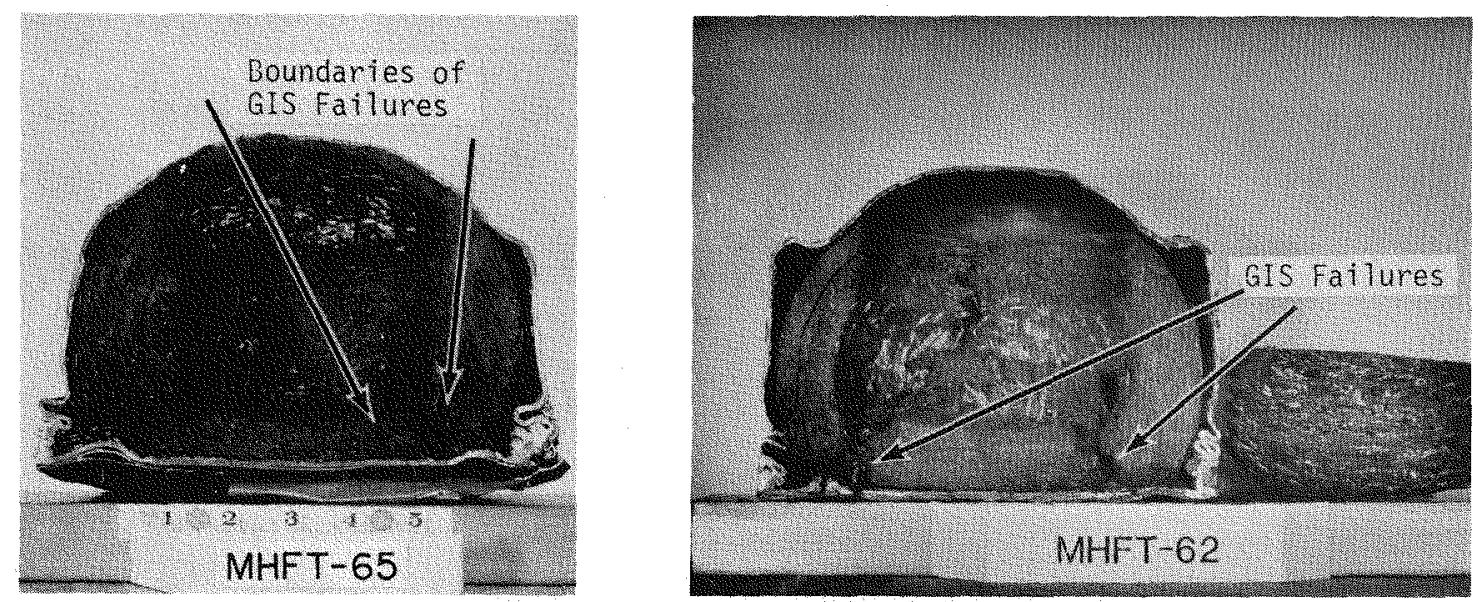

a. Sections of GIS's Used in MHFT 62 and $65^{*}$
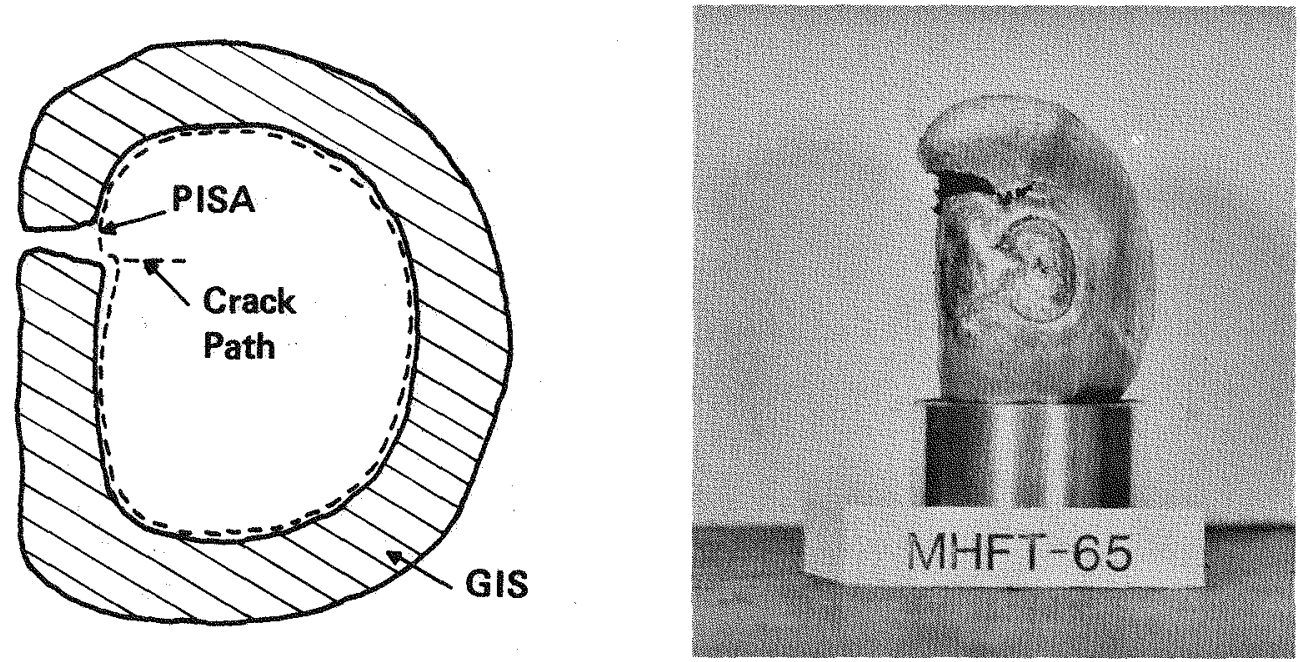

b. Schematic Drawing of GIS Showing How Failure in GIS Corresponds to c. Actual Profile of MHFT 65 Lobe in MHFT 65 PISA

\section{FIGURE 13. Evidence That Push-Through is Caused by Failure} of the GIS*

* Photographs, courtesy of D. Pavone, LANL. 
fuel into the separation in the GIS, not by shearing of large pieces of fuel with respect to each other. The actual profiles of cross sections of impacted PISAs and GISs support this mechanism. The mechanism is also supported by data on MHFT 70. There was large deformation of the PICS (although primarily at the back side) of MHFT 70, caused by shearing of two halves of the sphere. The GIS split, but the extent of the split is unknown; the existing photograph of the cross section does not show a split. Therefore, the opportunity for sandbagging of the fuel into a split cannot be assessed. However, the pronounced push-through lobes seen in MHFT 61 and 65 did not occur, reinforcing the idea that the lobes (which indicate excessive local strain) are the result of sandbagging into the gap of a failed GIS and not due to shear of large pieces along a pre-existing crack.

The implications for impact results of MHW spheres is that Spheres 35 through 53 may slide more easily, but no push-through should occur without failure of the GIS. Shear of large chunks along preexisting cracks is not expected unless the crack is essentially a smooth flat fracture plane as was the case of MHFT 70. Such fracture planes are not expected to be common. Even then, push-through failure should not occur if the GIS remains intact. For spheres of other production groups (from SRP No. 54 to the end of production), fracture planes were not well defined for those that were integral when encapsulated. These later spheres should impact essentially as if they had been integral; i.e., no unusual impact behavior is anticipated. For those spheres that had to be assembled before encapsulation, deformation of the iridium may be more severe, as was the case for MHFT 70, but failure should not occur if the GIS remains intact. The implication here is that impact failure is a function of random variations in the strength of the GIS. Certainly MHFT 70 showed that substantial latera1 thrust by shearing of the fuel pieces does not dominate the rupture tendency of the GIS (because the split in the GIS was not noticeably excessive and may have been slight). It is more likely that the cause of GIS rupture is a complex interaction of several impact parameters including GIS strength and fuel lateral thrust. Failure then occurs when the combined effects of these parameters exceeds a certain threshold.

\section{Friction and other Factors as Sources of Statistical Variability of Strain in Iridium}

We proposed a two-step mechanism of failure of MHFT 65: (1) failure of the GIS and (2) failure of the iridium to accommodate the resultant plastic strain as the fuel pushes into the gap in the GIS. These steps allow for opportunities for statistical variations in properties which could combine to produce a large failure. In step one, there could be variations in the strength of the GIS or variations in the lateral thrust. The latter variation 
would depend on how the sphere deformed, which would depend on the strength of the sphere and other factors such as very large flat fracture planes appropriately oriented. How much the strength varies among the GISs and the spheres is not known; nor is it known if the magnitude of strength variation among spheres is significant, compared to the large fracture energy that is available. It is expected that the role of large preexisting cracks is usually not first order for the reasons given above.

In step two, there are several prominant factors that could vary considerably and that affect the ability of the iridium to withstand the plastic strain. One of the most obvious is the previously discussed phosphorus (or possibly other impurity) content. Another is the time of failure of the GIS. This would affect the size of the gap in the GIS and the energy available to the PISA to sandbag into the gap. As these factors vary, they entail more or less strain in the iridium.

Another factor affecting step two, that has a large potential for variation, is friction at the interfaces of the GIS-iridium and iridium-fuel. This was spotlighted in the computer modeling study and may vary widely enough to cause failure or nonfailure at random among FSAs, especially those higher in phosphorus. For example, the difference in the calculated hoop strain with and without friction (Figure 14) is large enough to suspect possible effects to occur with variations in friction forces. 1

The computer simulation of FSA impacts 1 showed that as the interfacial friction between the GIS and iridium and the fuel and iridium increased, the amount of strain in the iridium increased. This is the result of locking of the iridium between the GIS and fuel so that the motion of the iridium relative to the GIS and the fuel is retarded. Because of this locking, the circumferential (from front around to back) deformation character of the iridium shell is altered, and the hoop strains are significantly increased (especially in the bend-over region where the flat impact face meets the curvature of the sides of the she11). Further, friction causes the circumferential strain to become tensile over most of the front flattened region of the iridium shell. When the coefficient of friction is zero, this strain is calculated by the computer model to be compressive, but becomes increasingly tensile as the coefficient of friction goes up. As the friction increases, the magnitude of the circumferential strain becomes of the same order as the maximum hoop strains and is largest in the area just before the bend-over region begins. There is also a very rapid change in strain rate in the iridium as the shell goes from compressive, very early in impact, to tensile as the impact face flattens out. Iridium is reported to be strain rate sensitive, with ductility decreasing with increasing strain rate. Differences in friction could arise from differences in the amount of dimpling 


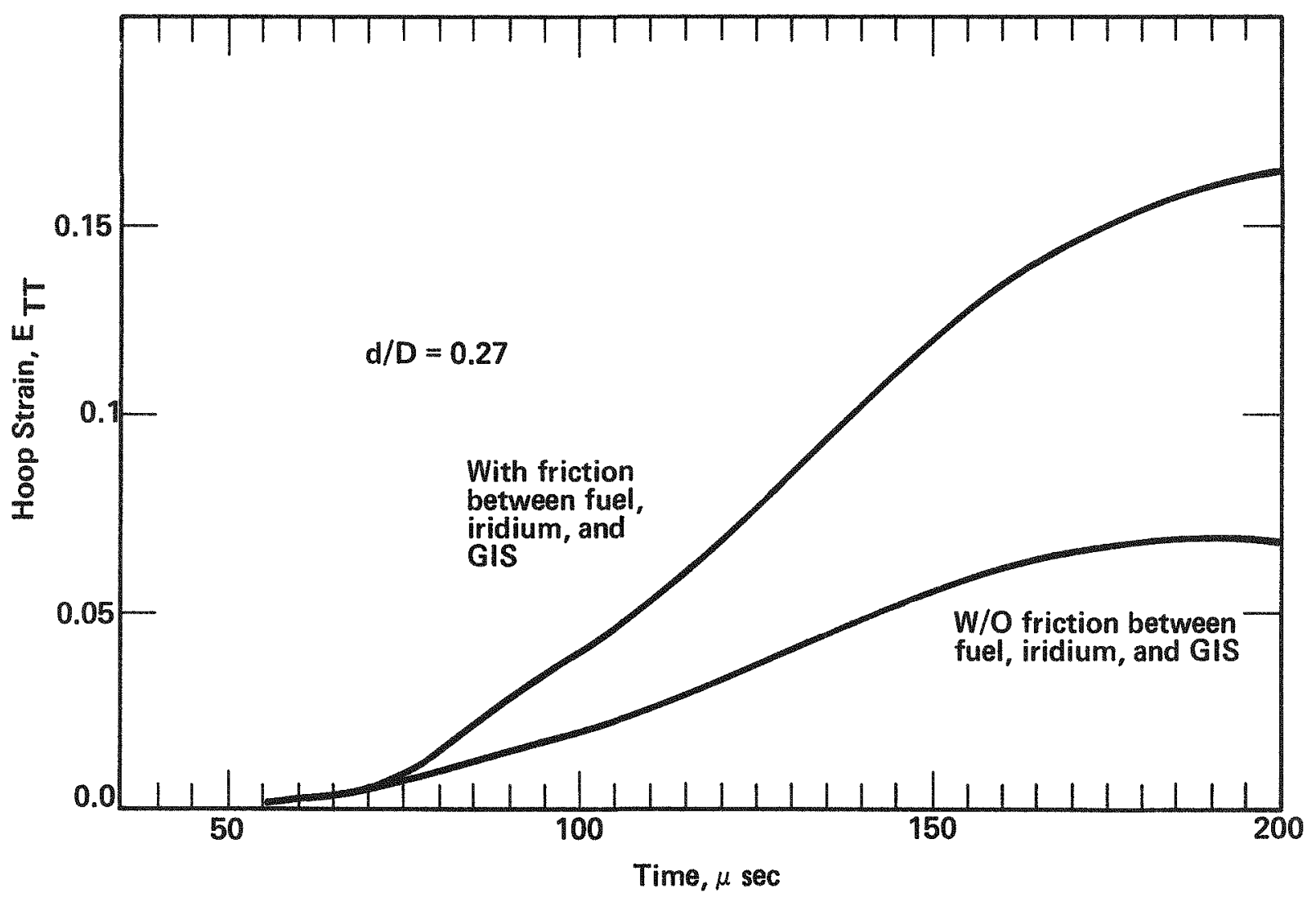

FIGURE 14. Comparison of Hoop Strain-Time Histories in the Iridium Zone 
on the impact face or the presence of vapor-deposited material on the inside surface of the iridium, as has been frequently observed. In one instance in particular (MHF 17, an old aged Mound Facility sphere), the fuel had swelled to fill the PICS and adhered tightly to the iridium via a vapor-deposited reaction layer.

In addition to variations in friction, there are also variations in the grain size and phosphorus distribution in the iridium. All of these effects could lead to substantial variability in the impact response of the FSA.

\section{ADDITIONAI, RESEARCH RECOMMENDED BY SR TASK PORCE MEMBERS}

\section{Characterization of Impurities in the Fuel (SRL)}

This characterization can be broken up into four areas for research: (1) pathways of phosphorus into the fuel; (2) stability of phosphorus in the fuel (e.g., rate of escape from the fuel); (3) process treatments that would eliminate the phosphorus prior to welding; and (4) agency-wide methods to analyze and monitor for phosphorus in the fuel.

\section{Pathways}

There are three pathways for phosphorus (or any impurity) to enter the fuel. The object of the research should be to find which pathway gives the highest phosphorus availability per unit of impurity content. The first is by precipitation of phosphorus along with the oxide from the feed solution. Here, the phosphorus may be bound within the lattice. The second pathway is by vapor transport from a phosphorus source. The phosphorus from this method is likely to be located along grain boundaries and on pore surfaces. Such phosphorus would, therefore, be expected to be more easily given up than if it were bound within the lattice. A third pathway is introduction, via some phosphorus-containing impurity, into the feed powder or granules. The phosphorus could then enter the Pu oxide lattice by diffusion, or be deposited along grain boundaries or pore surfaces by surface diffusion or vapor transport, or even remain bound to the impurity on the grain boundaries. This pathway into the lattice may have a phosphorus availability that is a mix of the first two. The research should at tempt to identify how the phosphorus is contained in the fuel (lattice or surface) and which source has the greatest contamination potential to the fuel. 


\section{Phosphorus Stability}

This research would measure the rate of escape from the fuel, or availability of the phosphorus picked up by each of the three pathways.

\section{Process Treatments}

Different methods for eliminating the phosphorus from the fuel during processing have been proposed and need to be evaluated. These are: vacuum outgassing and outgassing in hydrogen, oxygen, or inert gas streams. These atmospheres would also be useful to test the effect of substoichiometry on phosphorus availability.

\section{Phosphorus Analys is}

Standard SSMS techniques need to be employed and tested for maximum sensitivity. The techniques could be used by all the sites that may do analyses of FSA components.

\section{Effect of Phosphorus on Ductility of Iridium (ORNL)}

Additional tests should be run to confirm the "threshold" hypothesis. These tests should be set up according to statistical experimental design in order to recognize the effects of the following variables and their interactions: grain size of the PICS, thorium content, phosphorus or other impurity content, strain rate, and oxygen pressure.

\section{Impact Modeling}

Modeling studies of GPHS pellets should be done to help understand the influence of various factors (such as graphite strength, fuel strength, friction, impact angle, strain rates, and location of the FSA in the generator) on the impact behavior of pellets. As already seen, these studies can be helpful in understanding and interpreting impact data.

\section{Fueled Tests}

The following tests are recommended:

- Aging iridium-clad GPHS pellets having known phosphorus contents. For a long-term test, age four clad GPHS pellets: three having phosphorus contents ranging from background to 
high levels (for GPHS shards, 5 to $200 \mathrm{ppm}$ ) and one with high phosphorus and high concentrations of cations ( $\mathrm{Ca}, \mathrm{Al}, \mathrm{Si}$ ) commonly found at vents. Each clad pellet would be aged in a graphite-simulated GIS. After aging, the components would be analyzed and the phosphorus content compared with that measured before aging. These observations would allow an estimate of the transfer coefficient of phosphorus between the fuel and iridium cladding.

- Phosphorus-free GIS (suggested by MF). After treating a GIS to remove phosphorus, age both the GIS and PISA separately at high temperature, assemble and impact immediately after bringing to impact temperature. Repeat at least once. Examine the iridium, GIS, and fuel for phosphorus.

- Effect of substoichiometry. LANL has observed an increase in ductility of $\mathrm{PuO}_{2}$ with decreasing stoichiometry. It is suggested that an as-pressed GPHS pellet be impacted, to test for possible benefits of substoichiometry.

\section{SUMMARY AND CONCLUSIONS OF SRL EVALUATION}

In summary, although MHFT 65 was a catastrophic failure, the impact data to date suggest that SRP fuel/DOP-26 iridium impacts better - i.e., has fewer failures - than previously used MF fuel/undoped iridium. A significant factor in enhancing the possibility of impact failure is the presence of small amounts of phosphorus which may be present more in the SRP-LANL FSAs than in previous FSAs.

We have concluded that the lobe type push-through failure of MHFT 65 and the lobe type push-through deformation of other test spheres were caused by failures of the GIS, but the inability of the iridium to accommodate the deformation of MHFT 65 was caused by phosphorus embrittlement. We have concluded that the push-through does not occur by shearing action of large fuel pieces, but by sandbagging into the split in the GIS after it has failed. The resultant strain is severe but not enough, alone, to rupture the normal DOP 26 iridium. However, rupture can occur where phosphorus contamination has caused embrittlement. Therefore, for catastrophic failure to occur with future spheres, we conclude that the following conditions must be met:

- The GIS must fail in such a way as to allow lobe type pushthrough.

- Time of the GIS failure must be early in the impact event so that the PISA still has sufficient energy left to deform into the gap. 
- Phosphorus (or some other impurity) is present in the iridium at high enough levels for embrittlement.

Although the probability of another catastrophic failure cannot be calculated, the available data and recent SVT experience suggest to us that the MHFT 65 event was uncommon.

With fabrication of MHW fuel complete, there is little that can be done to ensure better impact rupture resistance. The two apparent "fixes" are to eliminate phosphorus and improve the strength of the GIS. Eliminating phosphorus is difficult because the source is not actually known. However, assuming the phosphorus comes from either the GIS or the fuel, the proposed methods of removal are mostly untried, and their effects on the system are unknown. For these reasons, the task force did not feel that attempting these fixes was justified.

The GIS design and material are fixed and cannot be changed at this point. Rupture of the GIS probably depends to some extent on how the sphere breaks up. However, the condition of the sphere, e.g., its crack network and sizes of chunks, appears to play only a secondary role. Extensive shear of large pieces along preexisting cracks is not expected to occur for spheres made after Sphere 53, except possibly those that were not integral and had to be assembled before encapsulation. However, even if shear of large masses does occur, impact test data suggest that such shear is not sufficient to cause lobe type push-through deformation or to rupture the GIS. Because preexisting cracks seem to exert only a second-order effect, it is expected that spheres from different PuFF production groups, which have different fracture resistance, should impact about the same (that is, have about the same probability of push-through failure). However, if the spheres from different production groups have any systematic differences in microstructure, there may be a systematic difference in GIS failure. Tests of spheres from these groups are needed to confirm such differences.

The effects of phosphorus should be confirmed and the source(s) of phosphorus in iridium located. It is possible that phosphorus may have to be rigorously eliminated to prevent embrittlement. Aging and impact tests should be carried out only for GPHS pellets with known phosphorus content. The effects of other impurities, such as sulfur, should also be investigated.

Modeling studies, as were done for MHW spheres, would be very useful in interpreting impact results of GPHS pellets. The interpretation of push-through given here for MHW is the result of impact data and computer modeling work for spheres. The application of this interpretation to the impact of GPHS fuel depends upon 1) the orientation of the fuel at impact (e.g., side-on vs. end-on) 
and 2) the similarity of the GIS materials of GPHS to those of MHW. For side-on impact of a GPHS pellet, the impact scenario described in this report for MHW may be a valid first approximation because both impacts have a circular profile in the $Y-Z$ plane (vertical plane perpendicular to the longitudinal pellet axis, see Figure 16). For end-on or near end-on impact of a GPHS pellet, the MHW impact model is not expected to be valid. However, in general it is clear - that the strengths of the fuel and GIS need to be complimentary for optimum impact performance.

There is evidence that excess oxygen in the fuel may degrade the ductility of the DOP 26 iridium by leaching out the thorium doped into the iridium to prevent grain growth. To help remove excess oxygen and possibly other impurities, the task force recommended that the heat-treated fuel also be vacuum outgassed before encapsulation. There is some evidence that vacuum outgassing may be helpful. 


\section{REFERENCES}

1. R. P. Swift, R. Brown, K. Wahi, and M. B. Eck. Fuel Sphere Assembly Deceleration Behavior During Impact: Calculations and Analyses. FSEC-ESD-217-75-63P, Fairchild space \& Electronics Company, Germantown, MD (October 1975).

2. Multi-Hundred Watt Radioisotope Thermoelectric Generator Program: 1976-1977 Annual Report/Final Report for the Voyager Program. Document No. GESP-7134, GEMS-430, Section 5, General Electric Co., Philadelphia, PA (1977). 
Copy №.

1-3 J. M. Bauer, DOE-SR

4-48 TIS File

49-263 Technical Information Center 